\title{
Estilos eruptivos asociados al volcanismo monogenético máfico de la región de Pasto Ventura, Puna Austral, Argentina
}

\author{
"Rubén Filipovich ${ }^{1}$, Walter Báez ${ }^{1}$, Emilce Bustos', Agustina Villagrán², \\ Agostina Chiodi', José Germán Viramonte ${ }^{1}$
}

\begin{abstract}
${ }^{I}$ Unidad de Recursos Geológicos y Geotérmicos del INENCO (UNSa-CONICET), Av. Bolivia 5150, A4400FVY Salta, Argentina. rubenfilipovich@yahoo.com.ar; geowbsalta@gmail.com; emilcebustos@gmail.com; agoch18@hotmail.com; joseviramonte@yahoo.com.ar 2 Instituto de Bio y Geociencias del Noroeste Argentino (UNSa-CONICET), 9 de Julio 14, 4405 Rosario de Lerma, Salta, Argentina. villagranagustina@gmail.com
\end{abstract}

*Corresponding author: rubenfilipovich@yahoo.com.ar

\begin{abstract}
RESUMEN. Uno de los rasgos más sobresalientes de la Puna Austral es el desarrollo de un volcanismo monogenético máfico durante el Neógeno-Cuaternario. Si bien existen numerosos trabajos que discuten la petrogénesis de este particular volcanismo de retroarco, los estudios enfocados en su volcanología física son escasos. En este sentido, este trabajo presenta una caracterización del volcanismo monogenético máfico de la región de Pasto Ventura, ubicada en el borde sudeste de la Puna Austral. Los resultados obtenidos indican que en la región de Pasto Ventura existe una baja densidad de centros eruptivos de pequeño volumen alineados con estructuras tectónicas regionales y una variabilidad significativa en los estilos eruptivos (efusivo, estromboliano, hawaiano, estromboliano violento y freatomagmático) y tipología de estructuras volcánicas (domos, conos de escoria, maares y anillos de tobas). La baja densidad de centros eruptivos se explica por un flujo limitado de magma desde la fuente profunda y la utilización de estructuras tectónicas, orientadas oblicuas a la dirección de compresión máxima, favorables para el ascenso de pequeños volúmenes de magma a través de la corteza superior. La variabilidad de estilos eruptivos responde a una interacción compleja de diferentes factores endógenos y exógenos. La ocurrencia de erupciones efusivas o explosivas depende de las diferencias en las velocidades de ascenso del magma, incluyendo períodos de estancamiento en la corteza superior, que a su vez controlan la eficiencia de la desgasificación y en última instancia la ocurrencia o no de fragmentación. Por otro lado, las condiciones climáticas locales más húmedas ( $\sim 150 \mathrm{~mm} / \mathrm{año}$ ), que se relacionan con la posición geográfica de la región de Pasto Ventura en el borde oriental de la Puna, favorecen la ocurrencia de actividad freatomagmática, la que a su vez varía en función de la topografía, tipología del substrato y profundidad a la que ocurre la interacción agua-magma.
\end{abstract}

Palabras clave: Volcanismo monogenético, Volcanología fisica, Control tectónico, Puna Austral.

\begin{abstract}
Eruptive styles related to the monogenetic mafic volcanism of Pasto Ventura region, Southern Puna, Argentina. One of the most outstanding features of the Southern Puna is the occurrence of a widespread monogenetic mafic volcanism during Neogene-Quaternary. Despite a number of published papers focusing on the petrogenesis of this back-arc volcanism, works aimed on its physical volcanology are scarce. This paper presents the characterization of the monogenetic mafic volcanism in the Pasto Ventura region, located in the southeast edge of the Southern Puna. The results show that in the Pasto Ventura region there is a low density of small-volume eruptive centers aligned with regional tectonic structures and a significant variability in eruptive styles (effusive, strombolian, hawaiian, violent strombolian and phreatomagmatic) and typology of volcanic structures (domes, scoria cones, maars and tuff rings). The first of these features is explained by a limited magma flow rate from the deep source and the use of favorable tectonic structures (oriented obliquely to the regional maximum compression direction) for the ascent of small volumes of magma through the upper crust. The variability of eruptive styles responds to the complex interaction of different endogenous and exogenous factors. The occurrence of effusive or explosive eruptions depends on the differences in magma ascent rates including periods of stagnation in the upper crust, which in turn control the efficiency of degassing and ultimately the occurrence of fragmentation. On the other hand, the more humid local climatic conditions ( $150 \mathrm{~mm} /$ year $)$, which are related to the geographical position of the Pasto Ventura region in the eastern edge of the Puna, favor the occurrence of phreatomagmatic activity. Phreatomagmatic activity also varies according to the topography, substrate typology and depth at which water-magma interaction occurs.
\end{abstract}




\section{Introducción}

El volcanismo monogenético produce, en general, volcanes de pequeño volumen con un amplio rango de estilos eruptivos, incluyendo estilos estrombolianos, hawaianos, estrombolianos violentos y freatomagmáticos (Valentine y Connor, 2015). Esta variabilidad en los estilos eruptivos se refleja en el desarrollo de diferentes tipologías de estructuras volcánicas, que incluyen conos de escoria, flujos de lavas fisurales, domos, pequeños volcanes en escudo, anillos de tobas (tuff rings), conos de tobas (tuff cones) y maares (Valentine y Connor, 2015). Estas estructuras volcánicas se encuentran de manera aislada o formando agrupaciones (clusters), y se localizan en los flancos de grandes estratovolcanes o constituyendo campos volcánicos, muchas veces alineados con estructuras tectónicas regionales (e.g., Connor y Conway, 2000; Lesti et al., 2008; Pardo et al., 2009; Németh, 2010). En la mayoría de los casos los volcanes monogenéticos se forman durante erupciones que pueden durar desde algunos días a decenas de años y comúnmente involucran pequeños volúmenes de magma $\left(<1 \mathrm{~km}^{3}\right)$ relacionados con sistemas de alimentación dispersos y relativamente simples, sin desarrollo de cámaras magmáticas en la corteza superior (Vespermann y Schmincke, 2000; Németh y Kereszturi, 2015). Sin embargo, numerosos trabajos (e.g., Németh y Kereszturi, 2015; Báez et al., 2017) han puesto de manifiesto la existencia de un amplio rango de estructuras volcánicas consideradas como monogenéticas, desde estructuras simples (volcanes monogenéticos sensu stricto) a estructuras formadas por múltiples erupciones separadas por hiatos de tiempo de decenas a miles de años (volcanes monogenéticos policíclicos) y/o con variaciones geoquímicas a lo largo de su evolución (volcanes monogenéticos polimagmáticos). La distribución espacial, tamaño, morfología y estilo eruptivo de los volcanes monogenéticos resultan de una compleja interacción de factores internos relacionados con las características intrínsecas del magma (composición, grado de cristalinidad, viscosidad, contenido de volátiles, etc.) y condiciones independientes del magma (tectónica regional y local, topografía, presencia de agua superficial y subsuperficial) relacionadas con el contexto geodinámico, propiedades físicas de las rocas y sedimentos que atraviesan el magma, así como con las condiciones ambientales superficiales (e.g., Lorenz, 2003; Németh, 2010; Németh y Kereszturi, 2015).
Uno de los rasgos más sobresalientes de la Puna Austral es el desarrollo de un volcanismo monogenético máfico durante el Neógeno-Cuaternario (Deruelle, 1978, 1982, 1991; Viramonte et al., 1984; Alonso et al., 1984; Allmendinger et al., 1989; Knox et al., 1989; Kay et al., 1994; Krallmann, 1994; Guzmán et al., 2006; Fig. 1) representado por una serie de agrupaciones o campos volcánicos (clusters) formados por domos, conos de escoria, anillos de tobas y maares. Si bien existen numerosas publicaciones que discuten la petrogénesis de este particular volcanismo de retroarco (Deruelle, 1991; Kay et al., 1994; Guzmán et al., 2006; Risse et al., 2008, 2013; Drew et al., 2009; Viramonte et al., 2010; Ducea et al., 2013; Maro, 2015; Murray et al., 2015; Schoenbohm y Carrapa, 2015; Maro et al., 2017b), los estudios enfocados en su volcanología física son escasos (e.g., Russo, 2010; Boltshauser, 2012; Báez et al., 2017). En este sentido, este trabajo presenta una caracterización del volcanismo monogenético máfico de la región de Pasto Ventura (Fig. 1), identificando las diferentes tipologías de estructuras volcánicas y estilos eruptivos asociados. El objetivo principal de esta contribución es definir los factores endógenos y exógenos que controlaron las variaciones en los estilos eruptivos, su distribución espacial y la morfología de los edificios volcánicos descritos. Por otro lado, mediante la comparación del volcanismo de la región de Pasto Ventura con otras agrupaciones de volcanes monogenéticos máficos de la Puna Austral, se propone un modelo conceptual integrado que explica la ocurrencia de este volcanismo en el contexto geodinámico del extremo sur de los Andes Centrales.

\section{Marco geológico}

\subsection{Volcanismo monogenético máfico de la Puna Austral}

Uno de los rasgos topográficos más sobresalientes de los Andes Centrales (16 $6^{\circ}-28^{\circ} \mathrm{S}$; Fig. 1A) es el desarrollo de una altiplanicie denominada plateau Andino o Puna-Altiplano (Isacks, 1988; Fig. 1A). Dentro del territorio argentino el plateau Andino constituye la provincia geológica Puna (Turner, 1972), ocupando las regiones occidentales de las provincias de Jujuy, Salta y Catamarca. La Puna se caracteriza por ser una altiplanicie con un nivel de base aproximado de $3.700 \mathrm{~m}$ s.n.m. (Isacks, 1988) y 


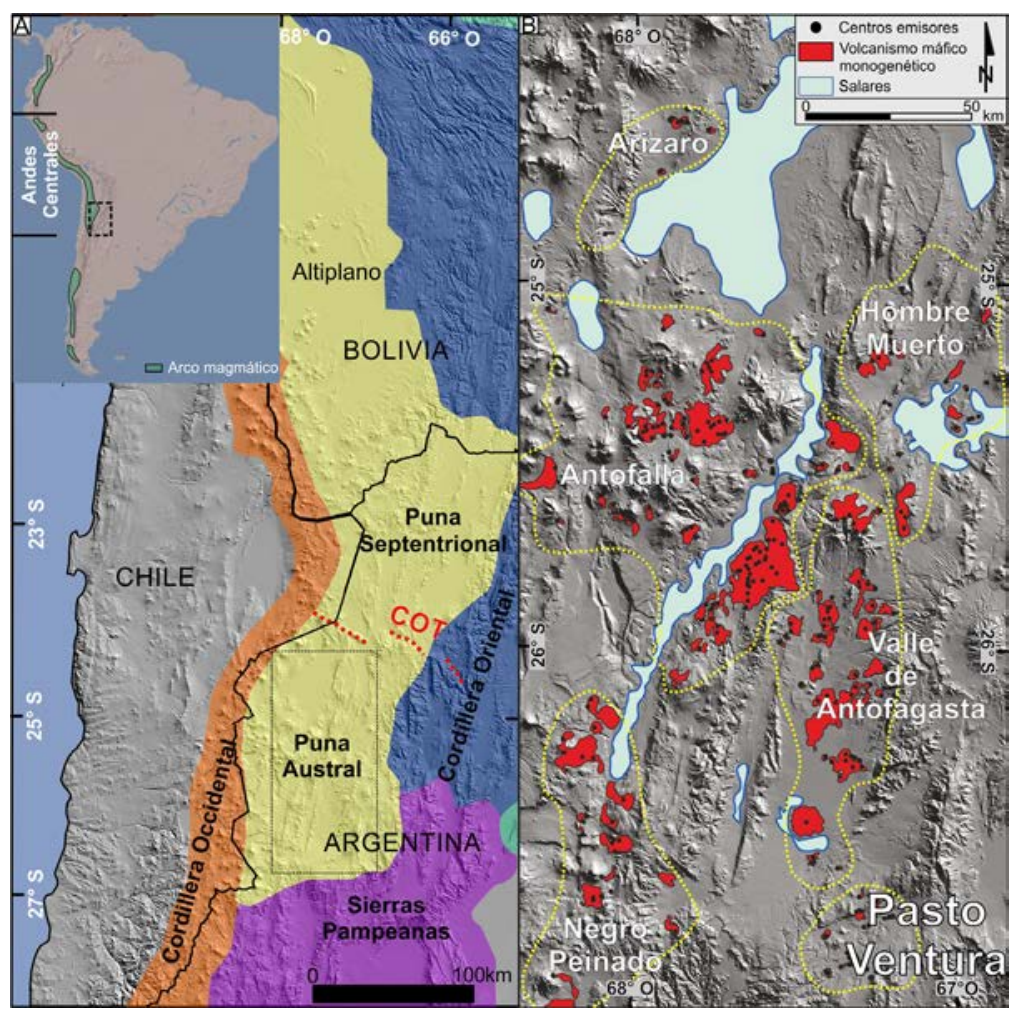

FIG. 1. A. Mapa de ubicación de la Puna Austral (modificado de Grosse et al., 2017). Recuadro superior izquierdo ubicación del plateau Altiplano-Puna dentro de los Andes Centrales. En la figura se indica el lineamiento COT (Calama-Olacapato-El Toro); B. Distribución espacial del volcanismo monogenético máfico de la Puna Austral (modificado de Maro et al., 2017a); la delimitación de las agrupaciones está basada en Viramonte et al. (2010).

limita al este con la Cordillera Oriental, al sur con la Sierras Pampeanas y al oeste con el arco magmático activo denominado Cordillera Occidental (e.g., Allmendinger et al., 1997; Fig. 1A). El lineamiento Calama-Olacapato-El Toro divide esta provincia geológica en Puna Septentrional y Puna Austral (Fig. 1A), las cuales se diferencian en función de variaciones en su actividad tectónica y magmatismo (e.g., Alonso et al., 1984).

El magmatismo de la Puna Austral está representado por tres asociaciones volcánicas diferentes (e.g., Viramonte et al., 1984; Coira et al., 1993; Kay y Coira, 2009; Guzmán et al., 2014; Petrinovic et al., 2017): i. Estratovolcanes andesíticos-dacíticos del Mioceno temprano al Holoceno en el arco principal y del Mioceno medio al Plioceno a lo largo de los lineamientos transversales al rumbo andino en el trasarco (e.g., Grosse et al., 2017), ii. ignimbritas y domos de composiciones dacíticas-riolíticas del Mioceno temprano al Holoceno, en la mayoría de los casos asociados a calderas de colapso, tanto en el arco principal como en la región de trasarco (e.g., Guzmán et al., 2017a), iii. Centros volcánicos monogenéticos máficos del Mioceno tardío al Holoceno en el trasarco (e.g., Maro et al., 2017a).

El volcanismo monogenético máfico se presenta en forma de conos de escoria, flujos de lavas, maares, anillos de tobas (tuff rings) y domos (Maro et al., 2017a). La mayoría de estas estructuras volcánicas tienen edades menores a $3 \mathrm{Ma}$, incluyendo algunas consideradas holocenas (e.g., Viramonte et al., 1984; Báez et al., 2017), aunque en algunos casos son más antiguas que $7 \mathrm{Ma}$ (Risse et al., 2008). Desde el punto de vista de las relaciones volcano-tectónicas el magmatismo máfico de la Puna Austral se asocia a fallas de rumbo y normales relacionadas con la presencia de una componente extensional N-S en el campo de esfuerzo regional que caracteriza a esta región desde el Mioceno Superior (Viramonte et al., 1984; Allmendinger et al., 1989; Marrett y 
Emerman, 1992; Montero López et al., 2010; Zhou et al., 2013). El volcanismo monogenético máfico de la Puna Austral, junto con el cambio desde un régimen compresivo a uno mixto con desarrollo de una componente extensional y la erupción de grandes volúmenes de ignimbritas dacíticas asociadas a la caldera del Cerro Galán, son considerados las evidencias superficiales más importantes que sustentan el modelo de delaminación litosférica propuesto para este sector de los Andes Centrales (Kay et al., 1994). Por otro lado, Viramonte et al. (2010) sugieren un posible rol del Alto Gravimétrico de los Andes Centrales (Central Andean Gravity High; Götze y Krause, 2002) en la distribución espacial y composición química de los agrupamientos de volcanes monogenéticos máficos (cluster). Desde el punto de vista petrogenético todos los autores están de acuerdo en que debe existir una fuente mantélica enriquecida para explicar las características geoquímicas de este volcanismo de trasarco; sin embargo existen diferentes posturas respecto a sus implicancias geodinámicas. La hipótesis clásica propuesta por Kay et al. (1994) sugiere que los magmas máficos de la Puna Austral son el resultado de la fusión del manto astenosférico debido a la descompresión adiabática sufrida durante su ascenso para ocupar el espacio generado por la delaminación de un gran bloque litosférico. Knox et al. (1989) y Kay et al. (1994) distinguen tres series basadas en las relaciones de elementos trazas incompatibles y contenido de $\mathrm{K}_{2} \mathrm{O}$. La serie más común y extensa, es la calcoalcalina (CA) que tiene altas razones de $\mathrm{La} / \mathrm{Ta}(>25)$ y Ba/Ta $(>300)$, la cual se interpreta como una serie fuertemente influenciada por los fluidos de la placa que subduce: a este grupo pertenecen las lavas de Pasto Ventura. Los basaltos de intraplaca (IP) o tipo OIB, constituyen una serie que tiene bajos valores de $\mathrm{La} / \mathrm{Ta}(<25)$, sugiriendo poca influencia de los fluidos de la placa que subduce, los cuales ocupan la parte central del trasarco de la Puna Austral. La tercera es la serie shoshonítica (SH), caracterizada por alto contenido en $\mathrm{K}_{2} \mathrm{O}$, y que está escasamente representada en el extremo norte de la Puna Austral. Según estos autores las variaciones geoquímicas de los magmas máficos de la Puna Austral reflejan grados variables de fusión parcial del manto astenosférico (intermedios-CA, altos-IP y bajos-SH, respectivamente). Los altos porcentajes de fusión parcial asociados al grupo de intraplaca serían el resultado de la delaminación de un gran bloque litosférico. Nuevos trabajos presentan una hipótesis alternativa en la cual el proceso de pérdida del material litosférico no es la delaminación de un gran bloque de litosfera, sino que se trata de un proceso de goteo (dripping) producto de inestabilidades de tipo Rayleigh-Taylor en el límite litosfera-astenósfera (Drew et al., 2009; Ducea et al., 2013). Estos autores proponen que existen dentro del manto litosférico anomalías de densidad representadas por cuerpos o cumulatos de piroxenitas asociadas al magmatismo de arco que afecta la región desde el Paleozoico. Las piroxenitas son comunes en la parte baja de la corteza o en el manto litosférico debajo de los continentes y son más densas que el manto circundante, por lo que son susceptibles de sufrir inestabilidades de tipo Rayleigh-Taylor y hundirse dentro del manto astenosférico en forma de gotas ( $<50 \mathrm{~km}$ de diámetro; Ducea et al., 2013). A diferencia de los modelos anteriores la fuente de los magmas máficos de la Puna Austral no sería el manto astenosférico sino la "gota litosférica" de composición piroxenítica que se hunde dentro del mismo (Drew et al., 2009; Ducea et al., 2013; Murray et al., 2015). Según Ducea et al. (2013) cada uno de los agrupamientos de volcanes monogenéticos (cluster) en el ámbito de la Puna Austral representa la remoción convectiva (sensu Göğüş y Pysklywec, 2008) de una "gota litosférica" individual, modelo que es sostenido por una serie de trabajos posteriores (Murray et al., 2015; Schoenbohm y Carrapa, 2015; DeCelles et al., 2015). Sin embargo, la idea de una fuente piroxenítica para los magmas máficos de la Puna Austral sigue siendo un tópico en discusión (ver Risse et al., 2013; Maro et al., $2017 \mathrm{a}, \mathrm{b}$ ). En cuanto a los procesos ocurridos durante la migración del magma desde la fuente mantélica y la erupción final de las lavas básicas de la Puna Austral, diversos autores proponen mecanismos de contaminación cortical durante el ascenso turbulento (ATA) para explicar las variaciones geoquímicas y el comportamiento aleatorio de las signaturas isotópicas (e.g., ${ }^{87} \mathrm{Sr} /{ }^{86} \mathrm{Sr}$ y $\left.\varepsilon \mathrm{Nd}\right)$, manteniendo características de magmas primarios (e.g., Guzmán et al., 2006). Particularmente para la zona de estudio, Risse et al. (2013) sugieren la existencia de dos reservorios intermedios dentro de la corteza donde ocurren procesos de cristalización y contaminación cortical. El primero ubicado en la corteza media (20-30 km) está evidenciado por cálculos termobarométricos de equilibrio clinopiroxeno-fundido. La presencia de un segundo nivel más superficial de acumulación y contaminación cortical está evidenciado por 
las discrepancias en los valores de elementos incompatibles dentro de los clinopiroxenos respecto a los de la roca total, por la fuerte correlación entre la variación en los valores de isótopos radiogénicos junto con el aumento del porcentaje de sílice y por las evidencias petrográficas de xenocristales de cuarzo parcialmente reabsorbidos. Risse et al. (2013) sugieren un promedio de $15-20 \%$ de contaminación cortical para los magmas máficos de la Puna Austral.

\subsection{Geología de la región de Pasto Ventura}

El basamento de la región de Pasto Ventura (Fig. 2) está constituido por rocas metamórficas de mediano a alto grado del Precámbrico-Paleozoico inferior intruidas por granitoides y cuerpos menores máficos a ultramáficos paleozoicos (e.g., Becchio et al., 1999; Seggiaro et al., 2006; Lucassen y Becchio, 2003; Suzaño et al., 2014). Sobre este basamento cristalino yacen sedimentos continentales de granulometría gruesa con niveles de paleosuelos intercalados, caracterizados por la ausencia de material volcánico en su composición y asignados al Eoceno superiorOligoceno inferior (Zhou et al., 2013, 2016; Zhou y Schoenbohm, 2015; Fig. 2). Estos depósitos representan la sedimentación en un área marginal (forebulge) de una cuenca de antepaís continua a escala regional (Zhou et al., 2016). Sobreyacen a estos depósitos

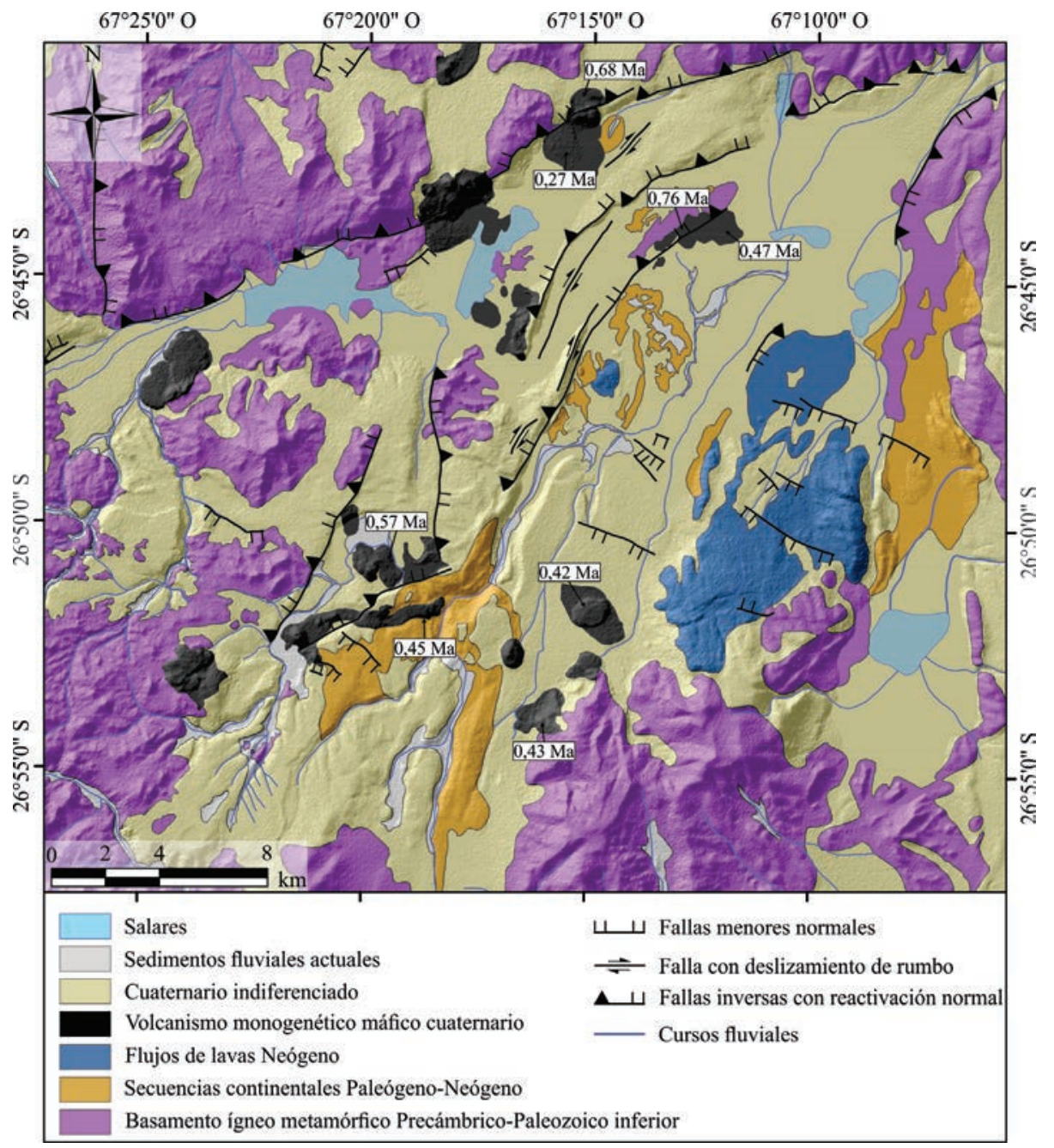

FIG. 2. Mapa geológico de la región de Pasto Ventura (modificado de Zhou et al., 2013). Edades absolutas tomadas de Zhou et al. (2013) y Zhou y Schoenbohm (2015). 
una serie de flujos lávicos andesíticos-basálticos (Fig. 2) con edades y composiciones similares al Complejo Volcánico Vicuña Pampa, ubicado hacia el este del área de estudio (Rossello, 1980; Viramonte y Petrinovic, 1999; Guzmán et al., 2017b, c). Entre los ca. 11,7 y los 7,8 Ma se desarrolló la cuenca de Pasto Ventura, cuya secuencia sedimentaria está formada por potentes depósitos continentales (Fig. 2) de color pardo rosado a rojo, compuestos por conglomerados, areniscas, limolitas, arcilitas y niveles de tobas intercalados (Ruiz Huidobro, 1975; Montero López, 2009; Zhou et al., 2013, 2016; Zhou y Schoenbohm, 2015). Durante el Cuaternario se desarrolló una importante actividad volcánica monogenética de composición básica (Figs. 2 y 3A), representada por flujos lávicos y material piroclástico asociados a estructuras volcánicas de pequeño volumen (conos de escoria, domos, maares y anillos de tobas), los cuales constituyen el objeto de estudio de este trabajo. Las edades disponibles sugieren que este volcanismo se desarrolló entre los $\sim 680$ y $\sim 270$ ka (Zhou et al., 2013). El cuaternario también está constituido por depósitos fluvio-lacustres de abanicos aluviales, dunas eólicas y material volcanoclástico (Zhou et al., 2013; Zhou y Schoenbohm, 2015; Fig. 2). Desde el punto de vista estructural, existen evidencias de que la cuenca de Pasto Ventura estuvo sometida a una deformación compresiva sindepositacional la cual se extendió al menos hasta los 4 Ma en dirección ONO-ESE a NO-SE (e.g., Montero Lopez et al., 2010; Zhou et al., 2013), momento en el que se infiere podría haber iniciado el cambio hacia un campo de esfuerzos mixto que incluye una componente extensional horizontal orientada NNE-SSO (Zhou et al., 2013; Zhou y Schoenbohm, 2015). Sin embargo, la evidencia disponible para Pasto Ventura solo permite afirmar que la componente extensional estuvo bien establecida en el Pleistoceno y que la misma se caracteriza por una tasa de deformación muy baja del orden de 0,02 a 0,08 mm/año (Zhou et al.,
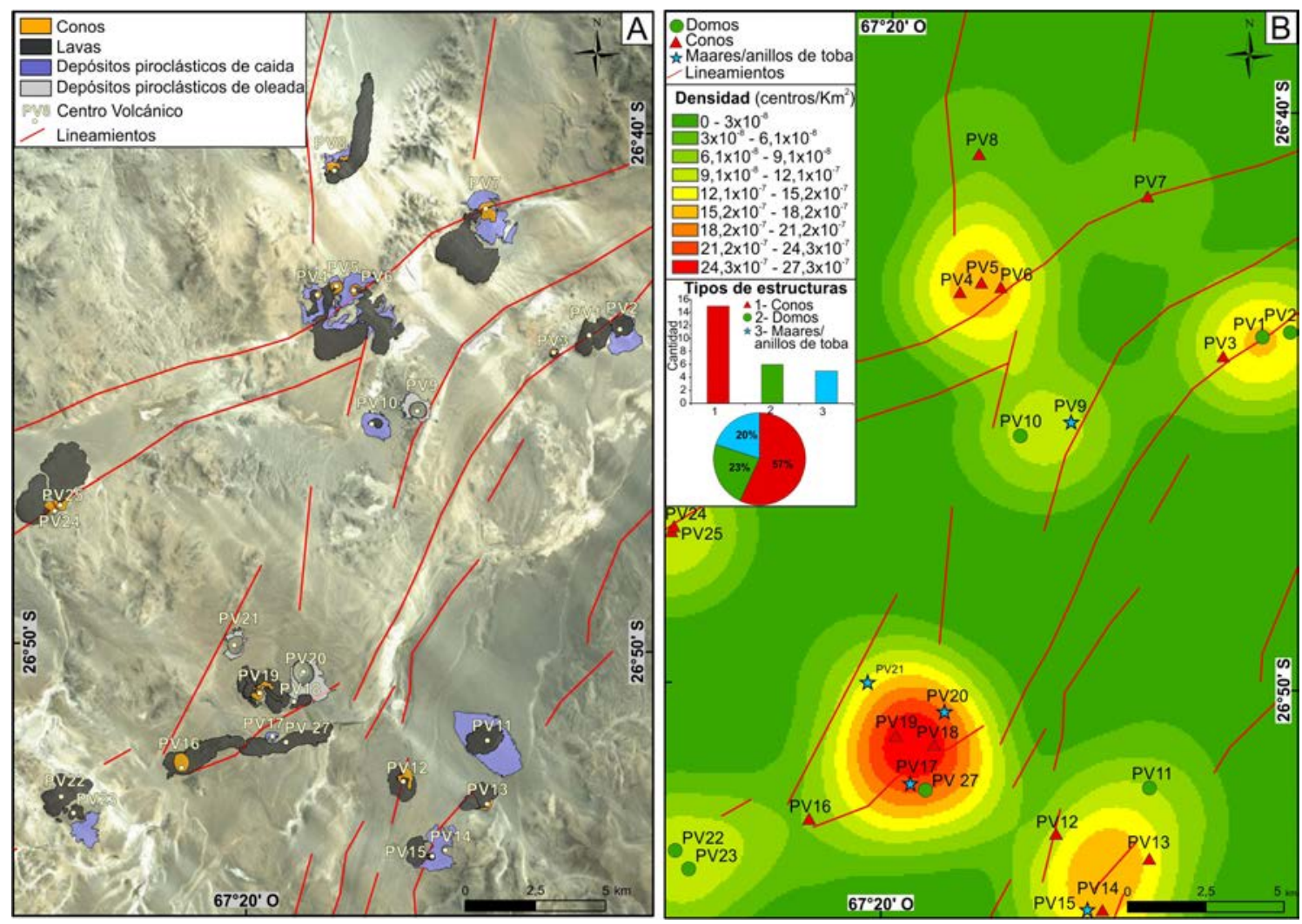

FIG. 3. A. Mapa esquemático del volcanismo monogenético máfico de la región de Pasto Ventura; B. Mapa de densidad de centros volcánicos y abundancia de las diferentes tipologías de estructuras volcánicas de la región de Pasto Ventura. 
2013; Zhou y Schoenbohm, 2015). Esta componente extensional reciente se expresa en la región de Pasto Ventura mediante la reactivación de fallas inversas previas (con cinemáticas normales y de rumbo) que afectan el basamento, orientadas principalmente en dirección NNE-SSO y NE-SO, así como con la generación de fallas normales menores, con escaso rechazo, que solo afectan la cubierta cuaternaria y están orientadas NO-SE (Zhou et al., 2013; Fig. 2). El evento compresivo mioceno superior seguido de extensión que se registra en la cuenca de Pasto Ventura ha sido interpretado como una deformación fuera de secuencia localizada, resultado de la delaminación de una "gota litosférica" de pequeñas dimensiones (Schoenbohm y Carrapa, 2015; Zhou y Schoenbohm, 2015; Zhou et al., 2016). Sin embargo, este evento compresivo ha sido reconocido en gran parte del extremo sur de la Puna Austral (e.g., Guzmán et al., 2014; Astini et al., 2018; Bustos et al., en prensa).

\section{Metodología}

Durante las tareas de campo se describieron y cartografiaron las diferentes estructuras volcánicas presentes en la región de Pasto Ventura. También se obtuvieron en terreno una serie de datos útiles para la posterior realización del análisis morfométrico y cálculo de volúmenes (espesores de coladas, alturas de conos de escoria, etc.; Apéndice tablas 1, 2 y 3). Por otro lado, se seleccionaron algunas estructuras volcánicas representativas del volcanismo de la región de Pasto Ventura en las cuales se definieron y describieron las diferentes unidades litoestratigráficas en función de características objetivas observables en el terreno (composición, estructura, textura, espesores, relaciones estratigráficas, morfología, etc.; Tabla 1) a las cuales se les asignó un nombre descriptivo sin implicancia genética (Cas y Wright, 1987). Posteriormente, se realizó el estudio petrográfico con microscopio óptico de polarización para la descripción composicional y textural de las diferentes litofacies. También se obtuvieron porcentajes modales de fenocristales, microlitos, vidrio y vesículas (Fig. 1 apéndice), mediante el método de conteo de puntos ( $\sim 350$ puntos/lámina delgada; DeHoff y Rhines, 1968). Para complementar la caracterización de las diferentes litofacies se realizaron ocho análisis geoquímicos de elementos mayores y trazas mediante fluorescencia de rayos X en la Universidad Nacional de Jujuy (Apéndice tabla 4), utilizando un espectrómetro secuencial Rigaku FX200 provisto de un tubo anticátodo de Rh de $3 \mathrm{~kW}$, operando a $50 \mathrm{kV}$ y $40 \mathrm{~mA}$. Una vez molidas y homogeneizadas las muestras, se fundieron con tetraborato de litio. La cuantificación de elementos mayoritarios se efectuó contra curva estándares homologadas por los servicios geológicos de Estados Unidos (SDC-1, SCO-1, BIR1, W-2, DNC-1, STM-1) y Japón (JG-2, JG-3, JA-3, JA-2, JB-3, JP-1, JR-2, JF-2). Asimismo, con el fin de realizar comparaciones, se recopiló toda la información geoquímica (Apéndice tabla 4) y petrográfica disponible de los distintos productos y centros volcánicos de la región (e.g., Kay et al., 1994; Drew et al., 2009; Risse et al., 2013; Murray et al., 2015). Además, se normalizaron los valores al $100 \%$ en base anhidra y se procedió a clasificar el conjunto de rocas con el diagrama TAS (total alkali silica) sensu Le Bas et al. (1986). Siguiendo la clasificación propuesta por Murray et al. (2015) para magmas máficos de la Puna Austral, se procedió a comparar $\mathrm{MgO}(\%)$ y $\# \mathrm{Mg}$ $\left[100\left(\mathrm{MgO} /\left(\mathrm{MgO}+\mathrm{FeO}_{\mathrm{t}}\right) \mathrm{mol} \%\right.\right.$; $\mathrm{FeO}_{\mathrm{t}}$ expresado en tabla 4 apéndice como $\mathrm{FeO}^{*}$ ] y a agruparlas según conos de escoria, domos y maares/anillos de tobas.

Las condiciones climatológicas de la Puna Austral (extrema aridez) mantuvieron las morfologías de las estructuras volcánicas prácticamente inalteradas, lo que facilitó la cuantificación de sus parámetros morfométricos mediante la integración de datos de campo con datos obtenidos a partir de imágenes satelitales ópticas (CNES/Astrium tomadas de Google Earth) y modelos digitales de elevación de acceso gratuito (ASTER GDEM y SRTM). El análisis morfométrico se efectuó siguiendo las recomendaciones de distintos autores (Wood, 1980; Wohletz y Sheridan, 1983; Corazzato y Tibaldi, 2006; Dóniz et al., 2008) dentro de un entorno SIG (ArcGIS 10). Particularmente, para el cálculo del volumen de los conos de escoria se utilizó la siguiente ecuación para conos truncados (e.g., Dóniz et al., 2008):

$V_{c o}=\frac{1}{3}\left[\pi \times H_{c o}\left(W b_{c o}^{2}+W s_{c r}^{2}\right)+\left(W b_{c o} \times W s_{c r}\right)\right]$

Esta considera altura (Hco) y diámetro de la base (Wbco) del cono, como así también diámetro menor del cráter (Wscr). Este último parámetro (Wscr), solo se pudo medir en conos completos, por lo que en el caso de conos de escorias aportillados se midieron de manera indirecta sobre la figura geométrica que mejor se ajustaba a la forma del cráter. Por otro lado, en el caso de las lavas asociadas a conos de escoria y domos, el volumen mínimo se estimó a partir del área 


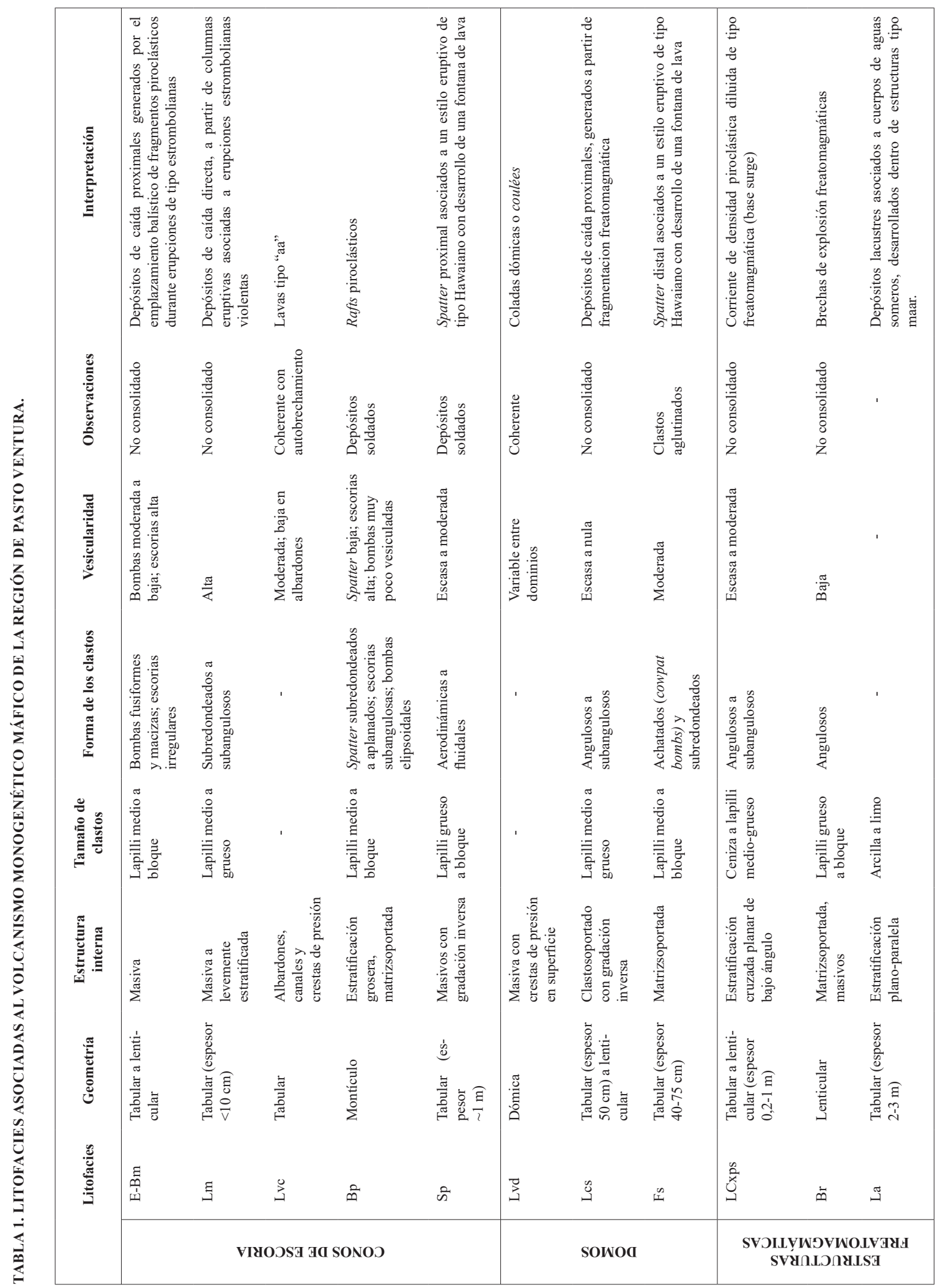


y espesor de las coladas considerando una superficie plana dada la geometría de las lavas y baja relación de aspecto de los domos.

Con el objetivo de analizar la distribución espacial del volcanismo monogenético máfico de Pasto Ventura y su relación con las estructuras tectónicas regionales se realizó un análisis morfoestructural y un mapa de densidad de centros volcánicos. El análisis morfoestructural se hizo mediante la extracción manual de lineamientos a partir de imágenes de relieve sombreado (hillshade) generadas con los modelos de elevación digital (ASTER GDEM-SRTM), siguiendo la metodología de Liu y Mason, (2009). El mapa de densidades se realizó con el módulo spatial analyst tools del programa ArcGIS 10.

\section{Resultados}

\subsection{Distribución espacial y relaciones volcano- tectónicas}

El volcanismo monogenético de la región de Pasto Ventura está caracterizado por la emisión de pequeños volúmenes de magma máfico $\left(0,42 \mathrm{~km}^{3}\right.$, volumen total de material emitido) e individualmente los centros eruptivos son pequeños (no superan los $0,2 \mathrm{~km}^{3}$, Apéndice tablas 1 y 2) comparados con los de otras agrupaciones volcánicas de la Puna Austral (e.g., Antofagasta de la Sierra, Báez et al., 2017). Otro rasgo característico es la variedad de estructuras volcánicas presentes: conos de escoria (57\%), domos (23\%) y estructuras freatomagmáticas $(20 \%)$ de tipo anillos de tobas (tuff rings) y maares (Figs. 3 y 4). Por otro lado, el volcanismo de Pasto Ventura también se caracteriza por una baja densidad de centros eruptivos $\left(2,43 \times 10^{-6}\right.$ centro $\left./ \mathrm{km}^{2} ; \mathrm{c} / \mathrm{km}^{2}\right)$ comparado con otros campos volcánicos monogenéticos $\left[1,15 \times 10^{-1} \mathrm{c} / \mathrm{km}^{2}\right.$ Pali Aike (Patagonia), 7,95x $10^{-2} \mathrm{c} / \mathrm{km}^{2} \mathrm{Abu}$ (Japón); Le Corvec et al., 2013]. En las figuras 2 y 3 se puede apreciar la distribución espacial de los distintos centros volcánicos, los cuales tienen una tendencia a agruparse a lo largo de las fallas inversas, orientadas principalmente NNE-SSO y NE-SO, reactivadas con cinemática normal y de rumbo, mientras que las fallas normales menores orientadas en dirección NO-SE no presentan estructuras volcánicas asociadas. El carácter sintectónico del volcanismo monogenético de la región de Pasto Ventura queda reflejado no solo por la distribución espacial, sino también por la asociación temporal de las estructuras volcánicas y las trazas de las fallas (Zhou et al., 2013).

\subsection{Morfometría}

Los parámetros morfométricos que se describen a continuación para conos de escorias, domos y maares/anillos de tobas se encuentran resumidos en el Apéndice tablas 1, 2 y 3 respectivamente.

\subsubsection{Conos de escoria}

Los conos de escoria alcanzan alturas (Hco) que varían entre 12 y $101 \mathrm{~m}$, abarcando áreas (Aco) de 0,01 a $0,29 \mathrm{~km}^{2}$ y volúmenes $(\mathrm{V})$ menores que $0,017 \mathrm{~km}^{3}$. En planta presentan geometrías circulares, subcirculares e irregulares con diámetros (Wbco) de 20 a $760 \mathrm{~m}$. Estas estructuras volcánicas pueden ser subdivididas en conos de escorias completos "tipo 1" y aportillados "tipo 2" (Figs. 5a, b). De los quince conos analizados, solo dos son tipo 1, en los cuales fue posible medir el grado de elipticidad de los cráteres ( $\mathrm{DCE}=$ Wscr/Wbcr; ver Apéndice tabla 1) denotando que los mismos tienen morfologías elongadas (elípticas) y subcirculares. Por otro lado, en los conos tipo 2 se midieron los valores de azimut del aportillamiento (BA), los cuales no se correlacionan con la dirección de las estructuras tectónicas principales de la región. Respecto a las pendientes determinadas (Sco), aproximadamente la mitad de los conos tienen valores típicos para conos de escoria $25^{\circ}-38^{\circ}$ (Vespermann y Schmincke, 2000) y la otra mitad valores por debajo de este rango. Esto se debe fundamentalmente al grado de preservación variable de los diferentes edificios volcánicos medidos. La morfología de los flujos lávicos es muy variada: alargados rellenando valles, expandidos en todas direcciones debido a pendientes suaves y otros que desarrollan formas deltaicas debido al cambio abrupto de pendiente.

A partir del análisis comparativo de los parámetros morfométricos con la orientación de las estructuras principales, se puede observar que de manera general no existe correlación entre estas y el azimut de la dirección de aportillamiento (BA) y elongación de los flujos de lava, debido a la topografía preexistente donde se emplazaron. El control tectónico sería válido solo si la pendiente es $<10^{\circ}$ (sensu Corazzato y Tibaldi, 2006). Por otro lado, únicamente en un centro volcánico (PV16) fue posible medir el azimut de la línea que se forma al unir los puntos deprimidos del borde del cráter (C-RDP; Corazzato y Tibaldi, 2006). Si bien el valor de C-RDP para este centro $\left(66^{\circ}\right.$; Apéndice tabla 1$)$ coincide con la orientación de los lineamientos tectónicos, lo que permite hacer inferencias acerca de la geometría y orientación de 


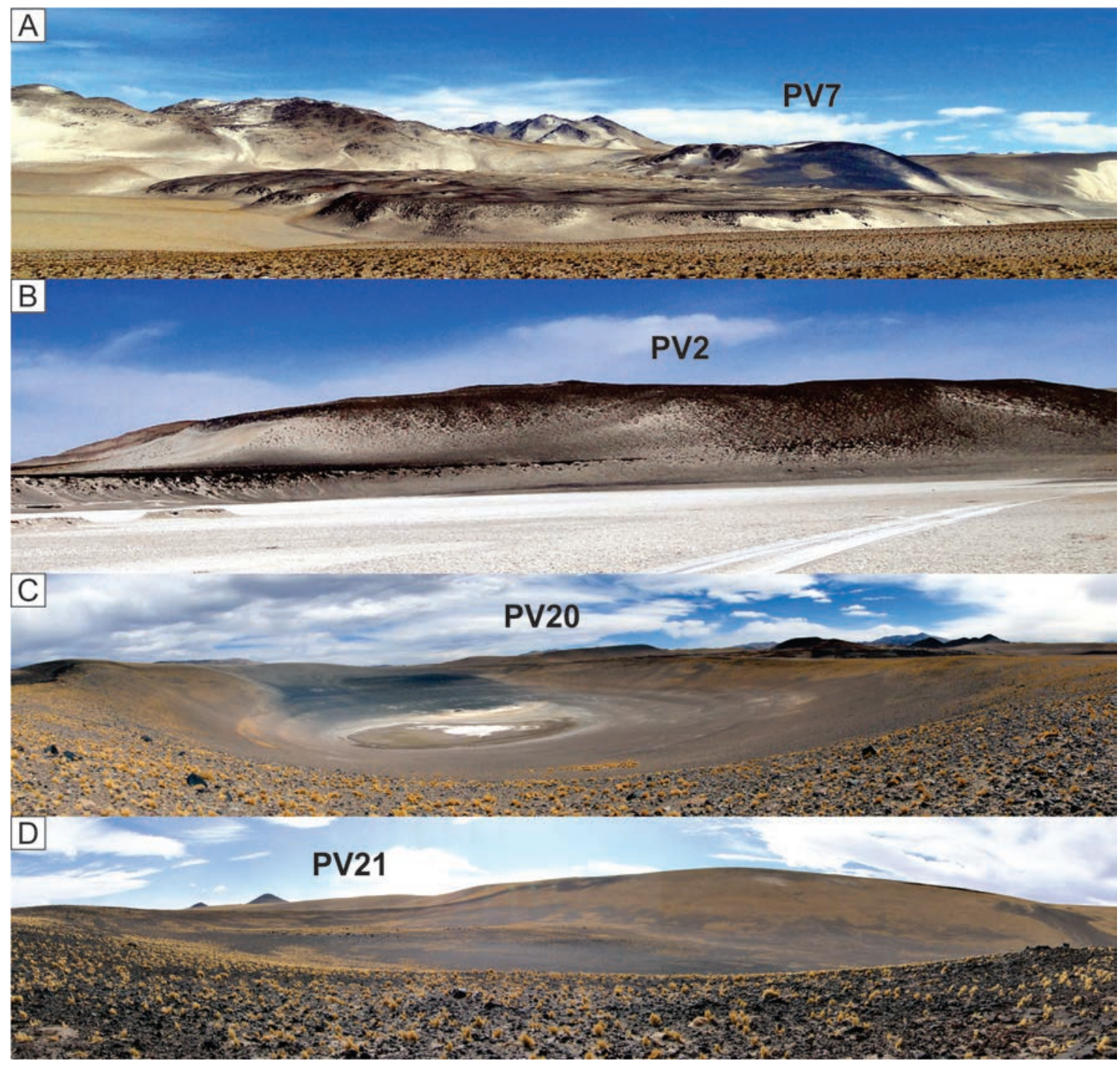

FIG. 4. Diferentes tipologías de estructuras volcánicas presentes en la región de Pasto Ventura. A. Cono de escoria; B. Domo; C. Maar; D. Anillo de tobas.

los diques que alimentaron a los conos de escoria (Corazzato y Tibaldi, 2006), se precisa de mayor cantidad de mediciones para darle un peso estadístico a esta afirmación.

\subsubsection{Domos}

Los domos se caracterizan por presentar en planta geometrías elípticas $(E<0,9)$ y circulares $(E>0,9)$ con alturas máximas (Hs) que alcanzan los $122 \mathrm{~m}$, abarcando áreas (A) desde $0,11 \mathrm{~km}^{2}$ hasta $1,44 \mathrm{~km}^{2}$ constituyendo estructuras de baja relación de aspecto de tipo "torta" (Fig. 5C). Los domos junto con las lavas asociadas a los conos de escoria representan la actividad efusiva de la región. Al igual que en los conos de escoria, algunos parámetros como el azimut del eje de máxima elongación (e) se correlacionan bien con los lineamientos tectónicos principales (ver Apéndice tabla 2). Sin embargo, en algunos casos (PV1 y PV23), la elongación del domo tiene un control topográfico, ya que las lavas emitidas fluyeron en favor de la pendiente local dando lugar a morfologías de tipo coladas dómicas o coulées (Fig. 5D). A partir del análisis morfológico, morfométrico y litofacial, junto con la frecuencia de ocurrencia, se reconocieron 


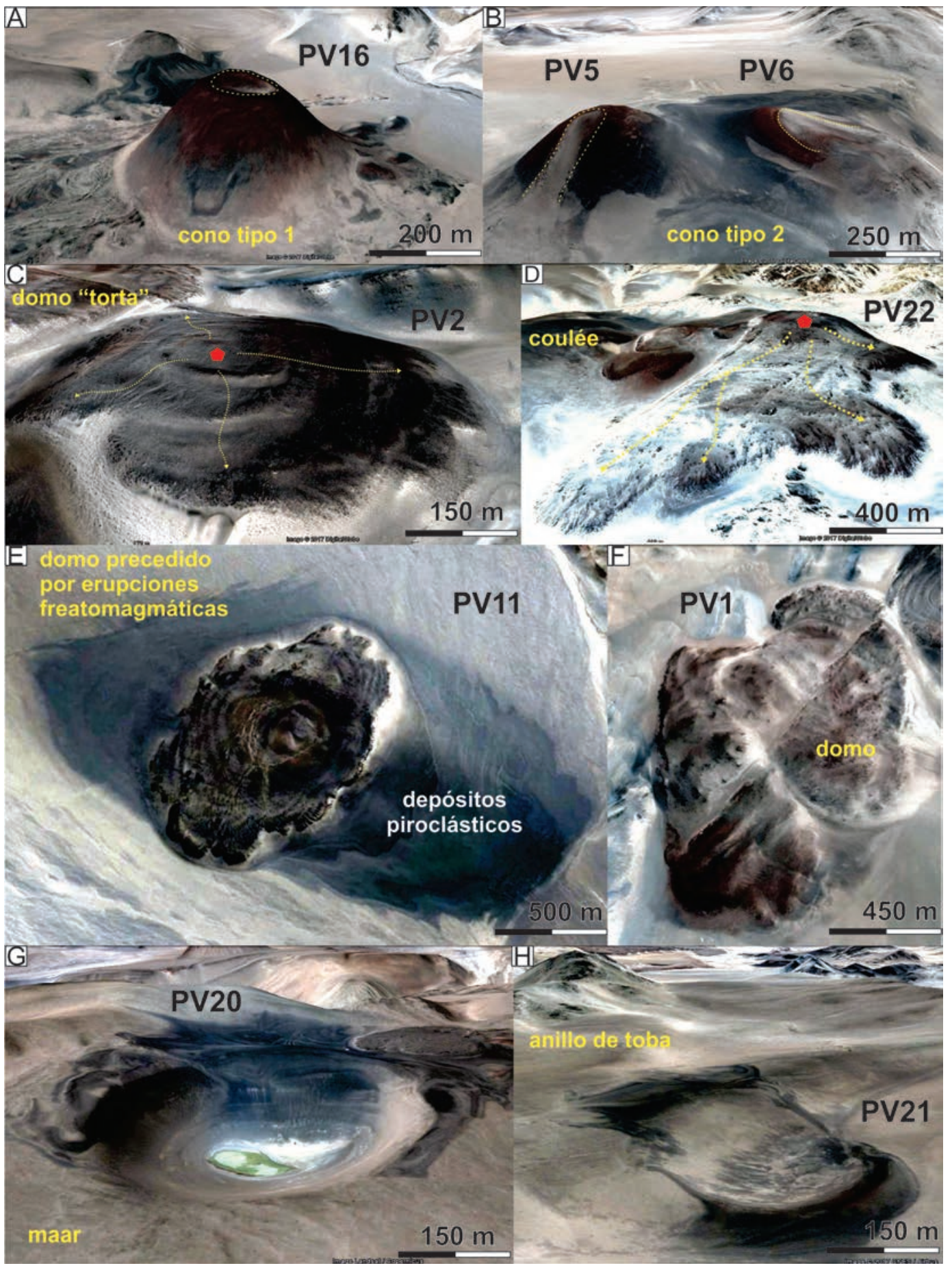

FIG. 5. Imágenes tomadas de Google Earth donde se observan las diferentes morfologías y tipologías de estructuras volcánicas presentes en la región de Pasto Ventura. Exageración vertical 3x. A. Conos completos "tipo 1"; B. Conos aportillados "tipo 2"; C. Domos tipo torta; D. Coladas dómicas o coulées; E. Domos precedidos por erupciones freatomagmáticas (Def); F. Domos no precedidos por erupciones freatomagmáticas (Dnef), atravesado por una falla de rumbo dextral.; G. Maar. Nótese la mayor profundidad del cráter en relación con la superficie topográfica original; H. Anillo de tobas. Nótese la ausencia de un cráter profundo, estructura solo constructiva respecto al nivel topográfico original. 
domos precedidos por erupciones freatomagmáticas (Def; Fig. 5E) y domos no precedidos por erupciones freatomagmáticas (Dnef; Fig. 5F).

\subsubsection{Maares/anillos de tobas}

Se identificaron dos maares y tres anillos de tobas (Fig. 3). Los primeros tienen diámetros de borde de cráter $(\mathrm{Dm})$ de 0,63 a $0,74 \mathrm{~km}$, cuyos depósitos llegan a cubrir áreas de hasta $1,03 \mathrm{~km}^{2}$ (Apy) con un radio máximo de distribución (Rpy) de $0,69 \mathrm{~km}$ y razones de profundidad/diámetro (H/D) siempre mayores a 0,02 (Fig. 5G). En contraste, los anillos de tobas tienen diámetros menores $(0,14-0,53 \mathrm{~km})$, sus depósitos llegan a cubrir áreas de hasta $1,11 \mathrm{~km}^{2}$ y la razón profundidad/diámetro del cráter no supera 0,02 (Fig. 5H).

\subsection{Análisis litofacial}

\subsubsection{Conos de escoria}

Facies masivas de escorias y bombas de tamaño lapilli a bloque (E-Bm). Son depósitos de color rojizo, no consolidados, masivos, muy mal seleccionados (lapilli medio a bloque) y formados por escorias y bombas con diferentes morfologías y grado de vesiculación (Fig. 6A). Estos depósitos constituyen el cuerpo principal de los conos de escoria. Las escorias (Es) son piroclastos de coloración roja o negra, vesiculares y con formas irregulares. Presentan tamaños mínimos de 3 a $5 \mathrm{~cm}$ con individuos que alcanzan $15 \mathrm{~cm}$ y tamaños promedio de $7 \mathrm{~cm}$ (Fig. 6B). Las bombas vesiculares (Bv) son de color rojo o negro, tienen tamaños entre 30 y $50 \mathrm{~cm}$ y poseen morfologías fusiformes o en cintas, en muchos casos plegadas de manera dúctil producto de la deformación por el impacto del eyecto en estado plástico contra el terreno (Fig. 6C). Hacia el núcleo de las bombas se observa un mayor grado de vesiculación, mientras que hacia afuera se observa el desarrollo de bordes vítreos de 1 a $2 \mathrm{~cm}$ (Fig. 6C) con estructuras en corteza de pan producto de la contracción por enfriamiento o de la expansión debido a la desgasificación tardía del núcleo (Wright et al., 2007). Las bombas masivas (Bm) son los componentes menos abundantes dentro de esta facies, son de color negro y poco vesiculares, tienen morfologías elipsoidales y globosas con un tamaño promedio de $60 \mathrm{~cm}$, alcanzando los $150 \mathrm{~cm}$ en algunos casos. Estos eyectos desarrollan estrías y canales en su superficie y están intensamente diaclasados.
En su conjunto la facies E-Bm se interpreta como depósitos de caída proximales generados por el emplazamiento balístico de fragmentos piroclásticos durante erupciones de tipo estrombolianas. En el caso de las escorias gran parte del transporte aéreo y emplazamiento ocurre en estado sólido y en el caso de las bombas en estado plástico. Las escorias y bombas con vesiculación representan las fases de mayor explosividad durante la erupción. En contraste, las bombas densas representarían la eyección de un magma desgasificado y más frío, el cual se encontraba acumulado dentro del cráter formando lagos de lavas durante las fases de menor explosividad (e.g., Hougthon y Schmincke, 1989; Presta y Caffe, 2014).

Facies masivas bien seleccionadas de lapilli (Lm). Son depósitos tabulares de pequeño espesor $(<10 \mathrm{~cm})$ que se distribuyen rodeando a los conos de escoria (Fig. 6A) y se acuñan rápidamente al alejarse de los mismos (máxima distancia alcanzada desde los conos: $700 \mathrm{~m}$ ). Son de color negro y están formados por fragmentos de escoria de tamaño lapilli medio a grueso, relativamente bien seleccionado, masivos a levemente estratificados.

Estos depósitos son interpretados como depósitos de caída directa a partir de columnas eruptivas asociadas a erupciones estrombolianas o estrombolianas violentas (Pioli et al., 2008).

Facies de lavas (Lvc). La mayoría de los conos tienen coladas de lavas asociadas con espesores entre 2 y $5 \mathrm{~m}$, y morfologías en planta elongadas, expandidas o deltaicas. Las mismas están formadas por rocas de color negro con texturas porfíricas, con fenocristales de olivino, piroxeno y plagioclasa en una matriz afanítica. También son abundantes los xenocristales de cuarzo y xenolitos de rocas del basamento ígneo-metamórfico. Dentro de las mismas es posible reconocer zonas de albardones con lavas poco vesiculares y coherentes, así como zonas de canal con lavas muy vesiculares y autobrechadas (Fig. 6D). En las zonas de canal se reconocen crestas de presión que indican las direcciones de flujo (Fig. 6D).

Las características reconocidas en las coladas durante las tareas de campo, así como las observadas mediante el análisis de imágenes satelitales de alta resolución, permiten inferir que todas las coladas de lavas en la región de Pasto Ventura son de tipo 'a'ā (cf. Harris et al., 2017).

Facies de bloques piroclásticos $(\mathrm{Bp})$. Son depósitos aislados dentro de la facies Lvc que se 


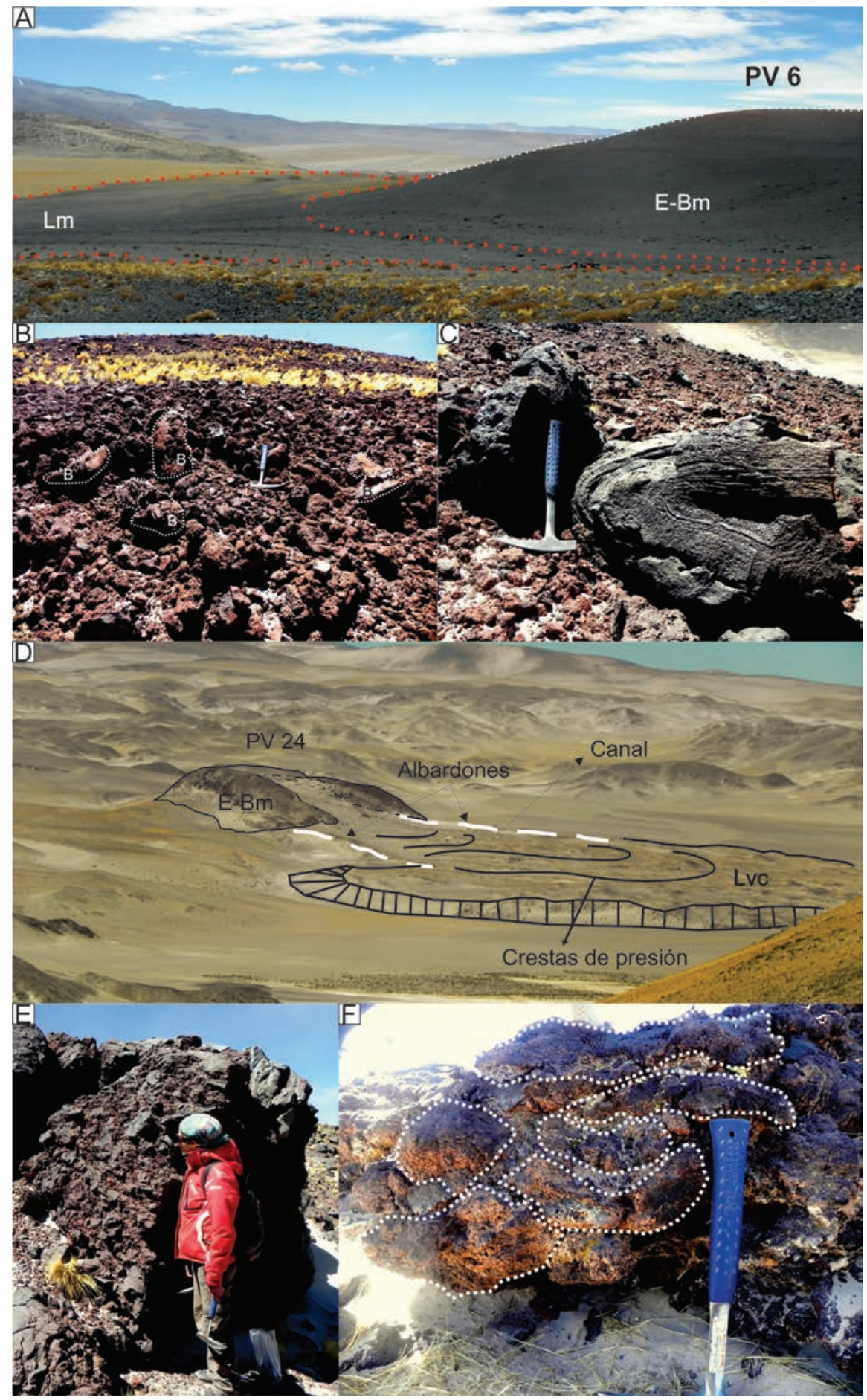

FIG. 6. Litofacies asociadas a los conos de escoria. A. Distribución de la facies masivas bien seleccionadas de lapilli (Lm) rodeando el cuerpo principal del cono de escoria (facies E-Bm); B. Facies masivas de escorias y bombas de tamaño lapilli a bloque (E-Bm). B: bomba; C. Bomba vesicular con morfología en cinta plegada por el impacto contra la superficie; D. Facies de lavas (Lvc) asociadas a los conos de escoria donde se reconocen morfologías típicas de flujos de lavas a‘ā; E. Facies de bloques piroclásticos (Bp) parcialmente soldada; F. Detalle de la facies de spatter (Sp). 
presentan en forma de montículos o bloques con tamaños que van de 1,40 a $2 \mathrm{~m}$, y volúmenes entre 1 y $2 \mathrm{~m}^{3}$ aproximadamente. Son de coloración rojiza, internamente tienen una estratificación grosera y están formados por spatters, escoria y bombas en una matriz lapillítica mediana a gruesa soldada (Fig. 6D).

Estos depósitos se interpretan como rafts piroclásticos (Holm, 1987) formados cuando la emisión de lavas desde la base del cono produce un colapso parcial del mismo. Los materiales del cono involucrados en el colapso son transportados como bloques que "flotan" sobre las lavas.

Facies de spatters (Sp). Son depósitos de color negro, soldados, con un espesor promedio de $1 \mathrm{~m}$ y morfología en planta elongada (Fig. 6F). Estos depósitos se ubican adyacentes a la estructura de los conos a lo largo de las mismas estructuras tectónicas que controlan su emplazamiento. Se infiere que esta facies se prolonga por debajo del cuerpo principal del cono (facies E-Bm) constituyendo una unidad subfrayacente. Internamente están formados por la acumulación de spatter de color negro, tamaño lapilli grueso a bloque, con escasa a moderada vesiculación (Fig. 6F). Estos eyectos de lava son expulsados en estado incandescente y al caer se deforman y aglutinan por las altas temperaturas que conservan al momento del impacto.

Esta facies se interpreta como depósitos de caída proximales asociados a un estilo eruptivo de tipo hawaiano con desarrollo de fontanas de lava (e.g., Valentine y Gregg, 2008).

\subsubsection{Domos}

Considerando la ocurrencia, disposición y relación estratigráfica de los depósitos asociados a los domos, se reconocieron facies previas al emplazamiento de los domos (facies predómicas) $\mathrm{y}$ facies dómicas.

\section{Facies dómicas}

Facies de lavas (Lvd). Se trata de lavas máficas coherentes que constituyen el cuerpo principal de las estructuras dómicas. En la superficie de los domos se reconocen crestas de presión concéntricas. Son rocas con texturas porfíricas formadas por fenocristales de olivino y piroxeno o anfíbol y piroxeno (dependiendo de la estructura dómica) en una matriz afanítica. En general son abundantes los xenocristales de cuarzo y xenolitos de rocas ígneas y metamórficas del basamento. Estas lavas se pueden separar sobre la base de su color en un dominio rojo y un dominio negro (Fig. 7A). La diferencia entre ambos dominios es un mayor grado de vesiculación y grado de alteración (oxidación) en el dominio rojo respecto al dominio negro. En algunos casos cada dominio ocupa un importante volumen del domo y están separados por contactos netos. En otros casos a escala centimétrica, se observa el desarrollo de sucesivas bandas de rocas de uno y otro dominio. Ambos dominios presentan la misma composición y proporción de fenocristales (los cuales varían en cada domo).

Los dos dominios descritos son interpretados como variaciones texturales resaltadas por la alteración y no implican ningún proceso de mezcla de magma. Alternativamente, este bandeado podría responder a tasas variables de desgasificación producto de un mecanismo de deformación continua que consiste en ciclos repetidos de deformación frágil y dúctil (e.g., Gonnermann y Manga, 2005). La distribución concéntrica de las crestas de presión sugiere una expansión radial de los domos desde el conducto emisor. Sin embargo, como se mencionó en el apartado de morfometría, en algunos casos se observa cierta asimetría en la morfología en planta de las crestas de presión concéntricas, rasgo que podría responder a un control topográfico. En este sentido, algunas estructuras volcánicas de la región de Pasto Ventura (e.g., PV1 y PV23), en donde la lava emitida tuvo movimiento lateral, podrían clasificarse como coladas dómicas o coulées (cf. Calder et al., 2015).

\section{Facies predómicas}

Facies de lapilli clastosoportado (Les). Son depósitos con una fábrica clastosoportada abierta, bien seleccionados, con gradación inversa, dispuestos en capas tabulares de $\sim 50 \mathrm{~cm}$ de espesor (Fig. 7B). Está compuesta por fragmentos lávicos de tamaño lapilli y hasta un $20 \%$ de bombas. Los fragmentos tamaño lapilli son juveniles de coloración oscura, con escasa a nula vesiculación, con formas angulosas a subangulosas y composiciones similares a las de la facie Lvd (variable en cada domo). Las bombas son densas, de color gris, están diaclasadas y tienen formas elipsoidales y tamaños entre 15 y $20 \mathrm{~cm}$.

Esta facies es interpretada como un depósito piroclástico de caída. La baja vesicularidad de todos los componentes sugiere que la fragmentación del magma fue originada por procesos freatomagmáticos (Lorenz, 1987). 


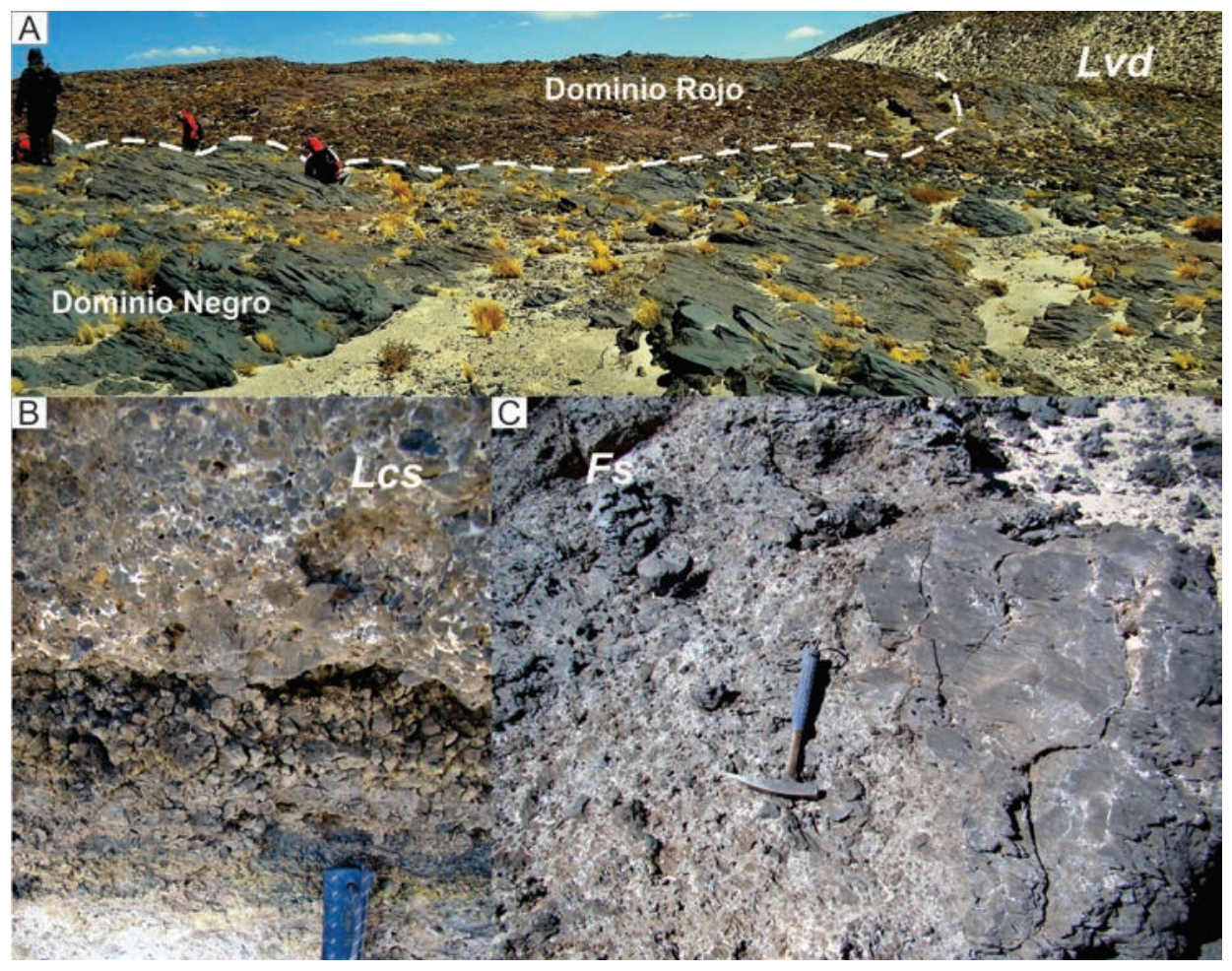

FIG: 7. Litofacies asociadas a domos. A. Fotografía de campo ilustrando los dos dominios presentes en la facies de lavas (Lvd); B. Afloramiento de la facies de lapilli clastosostenido (Les); C. Afloramiento de la facies soldada lapilli-bombas (Fs).

Facies soldada de lapilli-bombas (Fs). Son depósitos de color negro matrizsoportados, mal seleccionados y soldados (Fig. 7C), dispuestos en capas tabulares con espesores que varían entre 0,40 a $0,75 \mathrm{~m}$ y se acuñan lateralmente al alejarse del domo (máxima extensión lateral $150 \mathrm{~m}$ ). Está formada por fragmentos de spatter, bombas y bloques de escoria, en una matriz de tamaño lapilli formada por fragmentos juveniles muy soldados (Fig. 7C). Las bombas y spatters pueden alcanzar 1,7 m de diámetro y el porcentaje de la matriz tamaño lapilli no supera el $40 \%$. Algunas de las bombas presentan estructuras en corteza de pan por enfriamiento brusco. Todos los fragmentos líticos juveniles tienen composiciones similares a las de la facies Lvd.

La facies Fs es interpretada como depósitos de caída proximales emplazados esencialmente de forma balística y con un grado de fragmentación menor a la facies Lcs. En este sentido, el menor grado de fragmentación y las evidencias de emplazamiento a alta temperatura (soldadura del depósito) sugieren una fase de disminución o ausencia de agua involucrada en la fragmentación.

\subsubsection{Maares/anillos de tobas}

Facies con estratificación planar y entrecruzada de lapilli-ceniza (LCxps). Esta facies forma cuerpos tabulares con espesores que varían de 0,20 a $15 \mathrm{~m}$ (Figs. 8A, B) que afloran en los flancos de las estructuras volcánicas freatomagmáticas (maares/ anillos de tobas) y se acuñan rápidamente hacia zonas distales. La facies LCxps son depósitos piroclásticos de color gris a negro, formados por intercalaciones de niveles de tamaño ceniza y lapilli, matrizsoportados, que internamente desarrollan estratificación cruzada planar de bajo ángulo (Fig. 8A). Estos depósitos están constituidos por fragmentos juveniles poco vesiculares y fragmentos líticos accidentales del basamento. Los líticos juveniles son negros, poco vesiculares, subangulosos y tienen texturas porfíricas con fenocristales, que varían según cada uno de los maares/anillos de toba (Olivino-Piroxeno; PiroxenoAnfíbol; Plagioclasa, etc.). Los fragmentos líticos accidentales están formados por rocas ígneas y metamórficas similares a las del basamento aflorante en la región, pero su proporción dentro del depósito 
varía significativamente entre los depósitos asociados a maares $(\sim 60 \%)$ y los asociados a anillos de tobas $(\sim 15 \%)$. También se reconocen bombas/bloques de hasta $45 \mathrm{~cm}$ de diámetro (juveniles o líticos accidentales) que en muchos casos desarrollan estructuras de impacto deformando las capas subyacentes (Fig. 8B).

La presencia de estructuras tractivas, impactos de bloques/bombas y fragmentos juveniles poco vesiculares sugiere que estos depósitos se asocian a corrientes de densidad piroclásticas diluidas asociadas a erupciones freatomagmáticas (base surge) (Vespermann y Schmincke, 2000).

Facies de brechas masivas (Br). Esta facies se distribuye principalmente en los bordes de las estructuras volcánicas freatomagmáticas, aunque su mejor expresión se asocia a estructuras de tipo maares (Fig. 8C). Son depósitos masivos, mal seleccionados y matrizsoportados formados por

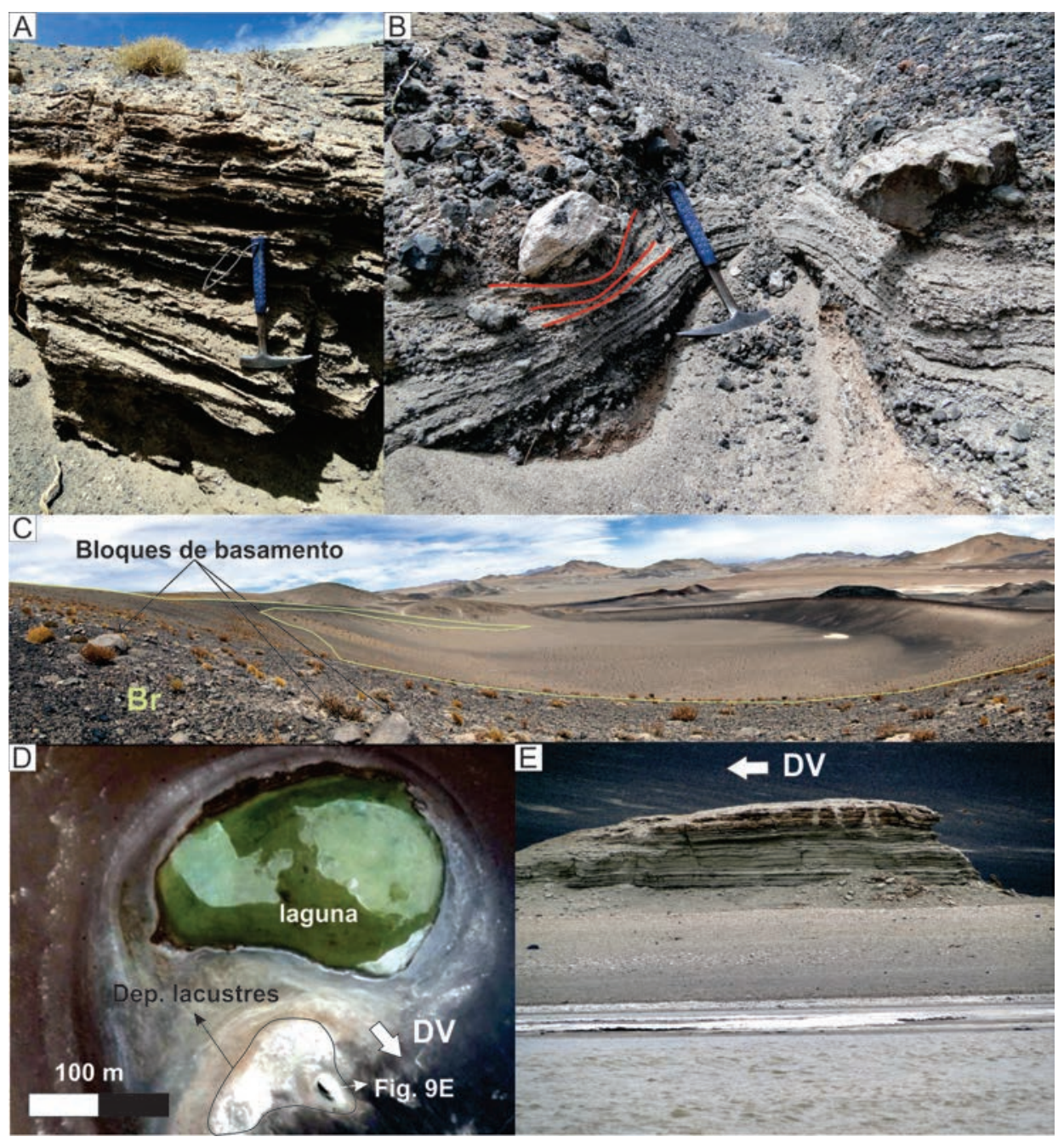

FIG. 8. Litofacies asociadas a maares/anillos de tobas. A. Afloramientos de la facies con estratificación planar y entrecruzada de lapilliceniza (LCxps) donde se observa el desarrollo de estratificación cruzada planar de bajo ángulo; B. Afloramientos de la facies LCxps donde se reconocen impactos de bombas. Las líneas rojas indican la deformación de la estratificación por impacto de bombas. C. Vista panorámica del maar PV9 donde se observa la distribución espacial de la facies de brechas masivas (Br) a lo largo del borde del cráter. Nótese la abundancia de fragmentos líticos de granitoides (basamento cristalino; tamaños 70-80 cm); D. Imagen Google Earth donde se puede apreciar la laguna y depósitos lacustres localizados dentro del maar PV 20 (ver Fig. 4c). DV: dirección de los vientos dominante; E. Afloramiento en forma de terraza de la facies de limos-arcillas laminadas (La) en el interior del maar PV20. 
bloques con tamaños que van desde $30 \mathrm{~cm}$ hasta $50 \mathrm{~cm}$ en una matriz tamaño lapilli grueso. Los bloques están formados por fragmentos líticos de rocas ígneas y metamórficas del basamento y por fragmentos juveniles poco vesiculares. La matriz lapillítica está formada por fragmentos juveniles densos y fragmentos líticos accidentales del basamento. La proporción de fragmentos líticos accidentales, al igual que en la facies LCxps, varía significativamente entre los depósitos asociados a maares $(\sim 80$ y $\sim 55 \%$ en la fracción bloque y lapilli, respectivamente) (Fig. 8C) y los asociados a anillos de tobas ( $\sim 20$ y $\sim 15 \%$ de fragmentos líticos accidentales en fracción bloque y lapilli, respectivamente) (Fig. 4D).

Su asociación con estructuras volcánicas de tipo maares/anillos de tobas, así como la presencia de fragmentos juveniles poco vesiculares, sugieren que estos depósitos constituyen brechas de explosión freatomagmáticas (Vespermann y Schmincke, 2000).

Facies de limos-arcillas laminadas (La). Se trata de depósitos bien estratificados que se disponen en cuerpos tabulares con espesores variables entre 2 y $3 \mathrm{~m}$ (Fig. 8E). Estos depósitos son de color blanco a blanco amarillento y están formados por una alternancia rítmica de paquetes de limo y arcilla. Esta facies se desarrolla solo en el interior de las estructuras de tipo maar, ocupando la parte central y formando afloramientos mesetiformes producto de deflación eólica (e.g., Roberts y Reed, 2009; Coronato et al., 2013) (Figs. 8D, E).

La facies La se interpreta como depósitos lacustres asociados a cuerpos de aguas someros desarrollados dentro de las estructuras volcánicas de tipo maar.

\subsection{Arquitectura interna de las estructuras volcánicas y estilos eruptivos asociados}

\subsubsection{Conos}

Las distintas litofacies identificadas en los conos de escoria de la región de Pasto Ventura se ajustan al modelo de distribución de facies para conos de escoria formados por erupciones estrombolianas (Vespermann y Schmincke, 2000). Según estos autores los conos de escorias desarrollan sectores externos caracterizados por depósitos no consolidados formados por bombas y escorias (facies E-Bm) y sectores internos soldados formados por spatter, escoria y bombas aglutinados. La destrucción del cono de escoria debido a la emisión de lavas produce el colapso de la estructura confiriéndole a la misma una forma de herradura. Así, en el caso de los conos relevados en este trabajo solo fue posible observar los sectores internos del cono de manera indirecta a partir de los rafts (facies Bp) transportados por las coladas de lavas. Del análisis morfométrico se infiere que la dirección de los colapsos fue controlada esencialmente por la inclinación de la topografía (Corazzato y Tibaldi, 2006). Las coladas lávicas de la facies Lvc que se generan a partir de numerosos conos relevados indican el carácter mixto (explosivo/ efusivo) de las erupciones que generaron los conos de escoria. En general, los conos de escoria estudiados tienen asociados una sola colada de tipo ' $a$ 'ā de morfología simple, formada por un canal principal y rupturas laterales menores. Solo el cono PV19 tiene una arquitectura más compleja, con múltiples coladas de lavas de tipo 'a'ā y superposición de dos conos sucesivos. La ocurrencia poco desarrollada y con escasa distribución areal de la facies Lm sugiere que los episodios estrombolianos violentos fueron puntuales y de corta duración, y no son responsables de la construcción del cuerpo principal de los conos de escorias, como sí ocurre en otros centros volcánicos máficos de la Puna Austral (e.g., Báez et al., 2017). Finalmente, la posición estratigráfica y distribución espacial de la facies Sp permiten inferir que la misma representa una fase inicial de la erupción con un estilo hawaiano y de tipo fisural.

\subsubsection{Domos}

Como se mencionó anteriormente, se identificaron domos precedidos por erupciones freatomagmáticas (Def; Fig. 5E) y domos no precedidos por erupciones freatomagmáticas (Dnef; Fig. 5F). En el caso de los domos Def, estratigráficamente por debajo de las estructuras dómicas, constituidas por la facies de lavas (Lvd), se desarrollan secuencias de depósitos piroclásticos de hasta $2,5 \mathrm{~m}$ de espesor formadas por las facies de lapilli clastosoportada (Lcs) y lapillibombas soldada (Fs) (Figs. 9A, B). Estos depósitos piroclásticos se disponen, de manera general, en capas tabulares que se acuñan a medida que se alejan del centro del domo (de manera más marcada en las facies Fs), con un arreglo granocreciente, aunque en algunos casos se observan dos o más ciclos granocrecientes superpuestos (Figs. 9A, B). La zona basal está dominada por la facies Lcs interpretada como depósitos de caída asociados a erupciones freatomagmáticas. Hacia la parte superior de la secuencia es mucho más abundante la facies Fs, caracterizada por una 

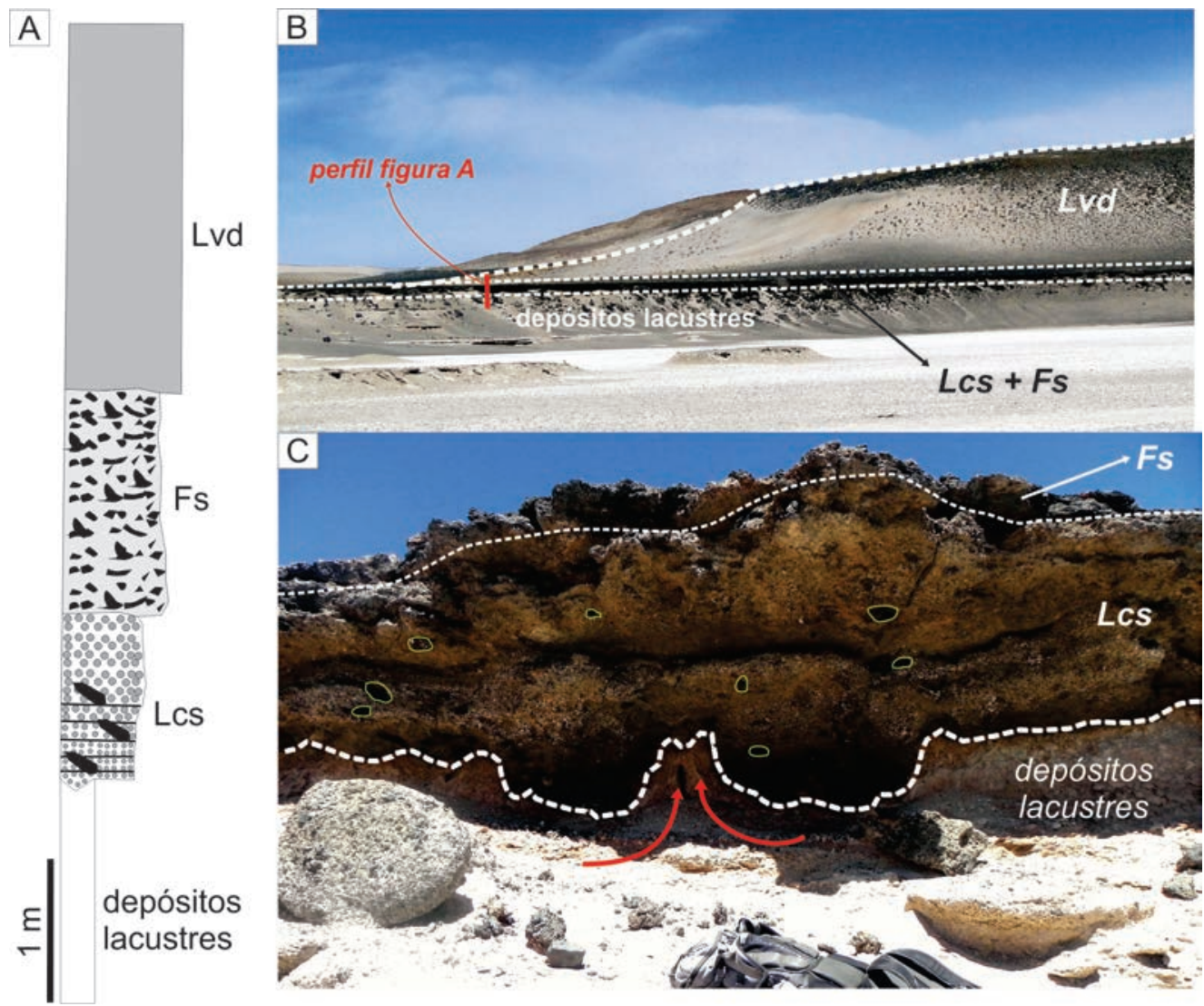

FIG. 9. A. Perfil esquemático de las secuencias piroclásticas asociadas a los domos precedidos por erupciones freatomagmáticas (Def); B. Vista panorámica del domo PV2 (Def) mostrando la distribución espacial de las diferentes facies; C. Afloramiento donde se observan estructuras de carga (resaltadas en la figura con línea discontinua) generadas por la rápida acumulación del material piroclástico sobre sedimento no consolidado saturado en agua, durante las fases freatomagmáticas asociadas a los domos Def. Las flechas rojas indican el desarrollo de estructuras generadas por carga. Dentro de la facies Lcs se resalta la presencia de bombas que alcanzan los $20 \mathrm{~cm}$, indicadas con líneas amarrillas de trazo continuo.

baja explosividad y menor grado de fragmentación respecto a la facies Lcs. Estas variaciones verticales de facies sugieren que en el caso de los domos Def su emplazamiento ocurrió luego de una fase explosiva inicial relacionada con la interacción del magma con agua externa. En algunos sectores se observa que la secuencia piroclástica se apoya directamente sobre depósitos lacustres desarrollando estructuras de carga (Fig. 9C). Las mismas se generan por la rápida acumulación del material piroclástico sobre sedimentos no consolidados y saturados en agua. Esto sugiere que la interacción agua/magma ocurrió dentro de un cuerpo de agua superficial que, dadas las condiciones climáticas de la Puna, probablemente fue muy somero. La vaporización progresiva del cuerpo de agua durante la erupción permitió un pasaje desde una fase muy explosiva (facies Lcs), a una fase de baja explosividad (facies Fs) y finalmente a una fase efusiva con el emplazamiento del domo representado por la facies Lvd. Esta interpretación es consistente con la ausencia de fragmentos líticos accidentales en las facies Lcs y Fs. Los domos generaron estructuras relativamente simples donde no se observan estructuras superficiales de tipo rampas, espinas o lóbulos internos limitados por zonas de cizalla, sugiriendo que su mecanismo de emplazamiento fue tipo endógeno (sensu Hale y Wadge, 2008). Como se mencionó anteriormente, cuando la efusión ocurrió sobre una topografía plana se formaron domos con morfologías chatas que se expandieron en forma radial desde el conducto emisor (domos torta). En contraste cuando la efusión ocurrió sobre una topografía inclinada 
las lavas fluyeron siguiendo la pendiente formando coladas dómicas o coulées.

\subsubsection{Maares/anillos de tobas}

La escasez de buenos afloramientos no permitió realizar correlaciones estratigráficas que permitan reconstruir la arquitectura litofacial interna de estas estructuras. Sin embargo, a partir de las observaciones de campo realizadas se pueden hacer inferencias respecto a los procesos operantes durante la formación de las estructuras volcánicas freatomagmáticas. Las facies de brechas masivas $(\mathrm{Br})$ caracterizan las zonas proximales en el borde de los cráteres de las estructuras freatomagmáticas. Sin embargo, esta facies está mucho mejor representada en las estructuras de tipo maar. Tanto en los maares como en los anillos de tobas en las zonas más distales son abundantes los depósitos piroclásticos con estructuras tractivas (facies LCxps). Ambas facies son ricas en fragmentos líticos en el caso de los maares y pobres en fragmentos líticos accidentales en el caso de los anillos de tobas. Estas características son consistentes con los mecanismos de formación de ambos tipos de estructuras. Los maares son estructuras que se desarrollan fundamentalmente por interacción agua/magma debajo del nivel topográfico preeruptivo, lo que explica la abundancia de fragmentos líticos accidentales en sus depósitos. En contraste, los anillos de tobas son estructuras constructivas desarrolladas sobre el nivel topográfico preeruptivo, por lo que sus depósitos tienen un bajo porcentaje de fragmentos líticos accidentales. Estas diferencias entre maares y anillos de tobas también explican la ocurrencia de cuerpos de agua dentro de los primeros.

\subsection{Petrografía y geoquímica}

Los términos utilizados para la descripción de secciones delgadas en este apartado siguen las propuestas introducidas por Whitney y Evans (2010): OI (olivino), Cpx (clinopiroxeno), Amp (anfíbol), PI (plagioclasa), Opq (opacos).

\subsubsection{Conos}

Las rocas pertenecientes a conos de escoria, tanto sus productos efusivos como piroclásticos, presentan texturas porfíricas con fenocristales de olivino, clinopiroxeno y plagioclasa subordinada inmersos en una matriz pilotáxica a intersertal, formada por microlitos de plagioclasa, clinopiroxeno, opaco y vidrio (Fig. 10A). Particularmente en las rocas lávicas asociadas a conos de escorias (facies Lvc), los fenocristales representan entre 24 y $30 \%$ de la roca (Fig. 1 apéndice). El olivino constituye el fenocristal más abundante (45-93,5\%) seguido por los de clinopiroxeno (6,5-35\%) y en algunos casos puntuales por fenocristales de plagioclasa (10,8-25\%) (Fig. 1 apéndice). Los microlitos (Pl, Cpx y Opq) en las muestras asociadas a los conos de escoria tienen porcentajes que varían desde 16 a $25 \%$ y tamaños entre 0,06 y $0,1 \mathrm{~mm}$ (Fig. 1 apéndice). También se observan de manera aislada xenocristales de cuarzo que desarrollan engolfamientos, coronas de reacción de clinopiroxenos y en ocasiones están, parcial a totalmente, reemplazados por agregados microcristalinos de clinopiroxeno. Las muestras pertenecientes a los conos de escoria tienen composiciones variables que van desde basálticas/ traquibasálticas a andesitas basálticas/traquiandesitas basálticas (Fig. 10E). En general los conos de escoria tienen una composición ligeramente más básica que el resto de las estructuras volcánicas de la región de Pasto Ventura, lo que se refleja en contenidos mayores de $\mathrm{MgO}, \mathrm{CaO}, \mathrm{FeO}_{\mathrm{t}}$ y $\mathrm{TiO}_{2}$. Dentro de la clasificación propuesta por Murray et al. (2015) para los magmas máficos de Puna Austral las muestras de conos se clasifican como "primitivas" y de "alto magnesio".

\subsubsection{Domos}

Las muestras pertenecientes a domos (facies Lvd), tienen texturas porfíricas con fenocristales de clinopiroxeno, proporciones variables de olivino y anfíbol inmersos en una matriz pilotáxica a intersertal, formada por microlitos de plagioclasas, clinopiroxenos, opacos y vidrio (Figs. 10B, C). El contenido de fenocristales varía entre 19 y $24 \%$ (Fig. 1 apéndice), y de acuerdo con la mineralogía predominante se diferenciaron dos grupos de rocas. El primer grupo (Cpx-Ol, Fig. 10B) está formado por rocas con fenocristales de clinopiroxeno $(59,6-$ $67,8 \%)$ y olivino $(40,4-32,2 \%)$ que en muchos casos se encuentran con bordes de reabsorción o con halos de óxidos. El segundo grupo (Amp-Cpx, Fig. 10C) está formado por rocas con fenocristales de anfíbol (90,2-92,4\%) y clinopiroxeno $(9,8-7,6 \%)$. Los microlitos ( $>90 \%$ plagioclasa) en las muestras asociadas a ambos grupos tienen porcentajes que varían desde 41,3 a $59,5 \%$ y tamaños entre 0,1 y $0,3 \mathrm{~mm}$ (Fig. 1 apéndice). Es común en las muestras de domos la presencia de xenocristales 

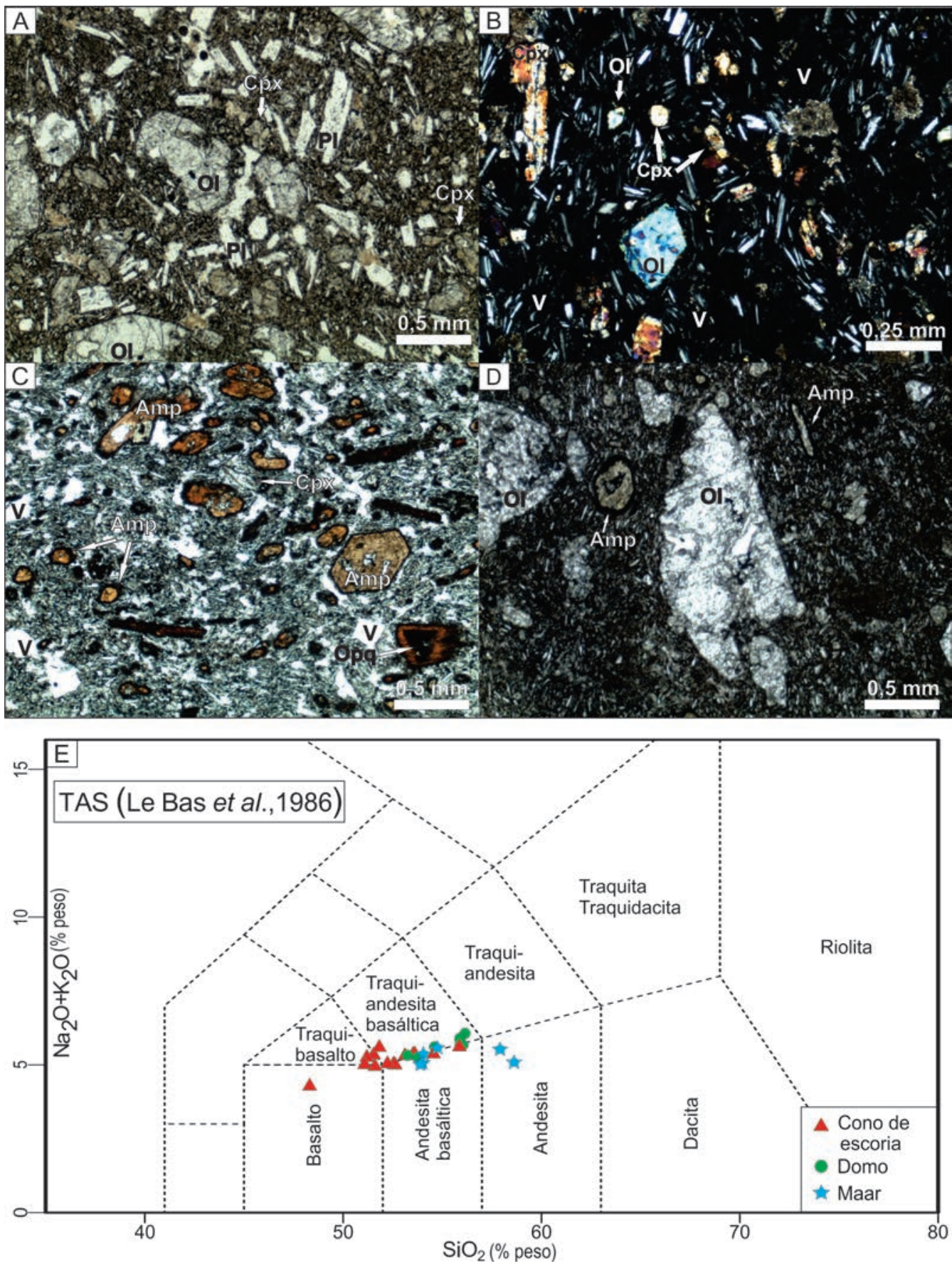

FIG. 10. Petrografía y geoquímica. Ol: olivino; Cpx: clinopiroxeno; Amp: anfíbol; Pl: plagioclasa; Opq: opacos; V: vesículas. A. Microfotografía (nicoles paralelos) donde se puede apreciar los rasgos texturales y mineralógicos de los fragmentos piroclásticos que constituyen los conos de escoria. B. Características petrográficas (nicoles cruzados) de las lavas que conforman los domos del grupo clinopiroxeno-olivino. C. Características petrográficas (nicoles paralelos) de las lavas que conforman los domos del grupo anfíbol-clinopiroxeno. D. Características petrográficas (nicoles paralelos) de un fragmento juvenil del grupo olivino-anfíbol asociados a estructuras freatomagmáticas. E. Clasificación geoquímica utilizando el diagrama de álcalis totales versus sílice (LeBas et al., 1986). Datos originales de este trabajo y tomados de Kay et al. (1994), Drew et al. (2009), Risse et al. (2013), Murray et al. (2015) (ver Apéndice tabla 4). 
de cuarzo que desarrollan engolfamientos, coronas de reacción de clinopiroxenos y en ocasiones están, parcial a totalmente reemplazados por agregados microcristalinos de clinopiroxeno. Los domos tienen variabilidad composicional más reducida, respecto a conos de escoria, ya que las rocas se clasifican como andesitas basálticas/traquiandesitas basálticas (Fig. 10E), siendo de manera general ligeramente más ácidos y con contenidos mayores de $\mathrm{Na}_{2} \mathrm{O}$ y $\mathrm{K}_{2} \mathrm{O}$ respecto a los conos de escoria. Las rocas se clasifican dentro del grupo "primitivo" propuesto por Murray et al. (2015).

\subsubsection{Maares/anillos de tobas}

Los fragmentos juveniles presentes en las facies LCxps y Br tienen diferencias texturales y composicionales en los diferentes maares/anillos de tobas, diferenciándose tres grupos de rocas. El primer grupo (Ol-Cpx) son rocas con texturas porfídicas formadas por fenocristales de olivino $(15 \%)$ y clinopiroxeno (10\%) los cuales están inmersos en una matriz hialopilítica de microlitos de plagioclasa y clinopiroxeno, minerales opacos y vidrio. El segundo grupo (Pl-Cpx) son rocas con texturas porfíricas con fenocristales de plagioclasa $(16 \%)$ y subordinadamente microcristales y fenocristales de clinopiroxeno (11\%) englobados en una matriz intergranular formada por microlitos de plagioclasa, minerales opacos y vidrio. El tercer grupo (Ol-Amp, Fig. 10D) son rocas con texturas porfíricas formadas por fenocristales de olivino (16\%) con bordes reabsorbidos y subordinadamente se encuentran microcristales y fenocristales de anfíbol (8\%) y xenocristales de cuarzo con coronas de reacción de clinopiroxenos, todo en una matriz intersertal a pilotáxica formada por microlitos de plagioclasa y vidrio (Fig. 10D). Esta variabilidad mineralógica y textural también se ve reflejada en una composición geoquímica variable de los juveniles asociados a maares/anillos de tobas, la cual abarca desde andesítica basáltica/ traquiandesítica basáltica a andesítica (Fig. 10E). Dentro de la clasificación propuesta por Murray et al. (2015) para los magmas máficos de Puna Austral todas las muestras de maares/anillos de tobas se clasifican en el grupo "primitivo".

\section{Discusión}

En síntesis, los resultados presentados en este trabajo ponen de manifiesto que el volcanismo monogenético máfico de la región de Pasto Ventura se caracteriza por dos aspectos fundamentales: i. una baja densidad de centros eruptivos $\left(<2,43 \times 10^{-6} \mathrm{c} / \mathrm{km}^{2}\right)$ de pequeño volumen alineados con estructuras tectónicas regionales y ii. una variabilidad en los estilos eruptivos y tipología de estructuras volcánicas. Estos dos aspectos resultan de la interacción de diferentes factores internos y externos que controlan la forma en que el magma finalmente se emplaza en la superficie (Kereszturi y Németh, 2012; Németh, 2010). A continuación, se discute el posible rol de diferentes factores en el control de la variación de los estilos eruptivos, tipología, distribución espacial y volumen de los centros volcánicos monogénicos máficos de la región de Pasto Ventura en el contexto geodinámico del extremo sur de los Andes Centrales.

\subsection{Factores que controlan la distribución espacial y volumen de los centros volcánicos}

Desde el punto de vista geodinámico es ampliamente aceptado que el volcanismo monogenético máfico de la Puna Austral se relaciona con el proceso de delaminación litosférica y el desarrollo de una componente extensional en el campo de esfuerzos regional para este sector de los Andes Centrales (Viramonte et al., 1984; Marrett y Emerman, 1992; Kay et al., 1994; Risse et al., 2008; Drew et al., 2009; Risse et al., 2013; Zhou et al., 2013; Ducea et al., 2013; Maro, 2015; Murray et al., 2015; Schoenbohm y Carrapa, 2015). Sin embargo, cerca de la superficie, donde el comportamiento reológico de la corteza es frágil, el ascenso rápido y turbulento de los magmas máficos está controlado fundamentalmente por la presencia de estructuras tectónicas preexistentes y en menor medida por el campo de esfuerzos regional (e.g., Alaniz-Álvarez et al., 1998; Guzmán et al., 2006; Maro et al., 2017b). En este sentido, Báez et al. (2017) proponen un modelo conceptual para explicar las variaciones en la distribución espacial y volumen del volcanismo monogenético máfico de la región de Antofagasta de la Sierra, en el cual se pondera el efecto de la delaminación litosférica, el campo de esfuerzos regional y la interacción de los magmas máficos con las estructuras tectónicas preexistentes. Siguiendo este modelo conceptual se puede explicar de manera satisfactoria la ocurrencia de una baja densidad de centros eruptivos de pequeño volumen alineados con estructuras tectónicas regionales en la región de Pasto Ventura (Fig. 11). Por un lado, la 
región de Pasto Ventura se ubicaría en una posición marginal respecto a la región donde se focalizó la delaminación de un gran bloque litosférico (e.g., Kay et al., 1994; Risse et al., 2013) o de forma alternativa sobre una zona afectada por la remoción de un pequeño bloque o "gota" litosférica (e.g., Drew et al., 2009; Ducea et al., 2013; Murray et al., 2015). Ambas situaciones darían como resultado un flujo de magma limitado desde la fuente profunda explicando la baja densidad y pequeño volumen del volcanismo monogenético máfico (Fig. 11). Por otro lado, la orientación NE-SO de las estructuras tectónicas principales de la región de Pasto Ventura es oblicua a la dirección de compresión máxima regional ( ONO-ESE; Riller y Oncken, 2003; Montero López et al., 2010; Zhou et al., 2013), por lo que serían propensas a ser reactivadas por la componente extensional del campo de esfuerzos reciente (e.g., Allmendinger et al., 1989; Zhou et al., 2013) y por ende más favorables para el ascenso rápido de pequeños volúmenes de magma, que de otra manera no tendrían la capacidad de ascender hasta la superficie (Fig. 11). Esta interpretación es consistente con la fuerte asociación espacio-temporal entre las estructuras tectónicas principales y el volcanismo máfico de la región de Pasto Ventura (e.g., Zhou et al., 2013), por lo que podría definirse como un campo volcánico controlado por tectónica (sensu Németh, 2010). Esto explica, también, la ocurrencia en la región de Pasto Ventura de los magmas máficos más primitivos de la Puna Austral (Drew et al., 2009). En contraste, otras agrupaciones como la región de Antofagasta de la Sierra (Fig. 1B) tienen una elevada densidad de centros volcánicos de mayor volumen que los presentes en el área de Pasto Ventura, los cuales se relacionan con un importante flujo de magma desde la fuente profunda debido a su posición sobre una región afectada por la delaminación de un gran bloque litosférico (Báez et al., 2017; Fig. 11). En este contexto es posible que los magmas máficos utilicen estructuras tectónicas regionales orientadas $\mathrm{N}-\mathrm{S}$ menos favorables para el ascenso del magma y/o que se desarrollen reservorios magmáticos dentro de la corteza superior que alimenten, mediante hidro-fracturas, volcanes monogenéticos de mayor tamaño y de tipo policíclicos/polimagmáticos (Báez et al., 2017; Fig. 11). En este sentido, el volcanismo monogenético máfico de la región de Antofagasta de la Sierra podría definirse como dominado por aporte magmático alto (sensu Németh, 2010).

\section{A: Campos volcánicos controlados por estructuras tectónicas preexistentes (Pasto Ventura)}

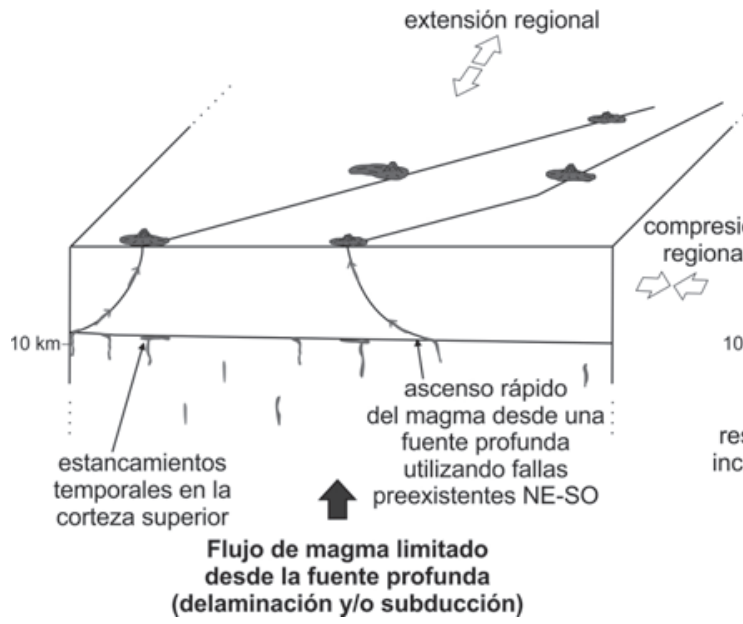

\section{B: Campos volcánicos controlados por aportes magmáticos altos (Antofagasta de la Sierra)}

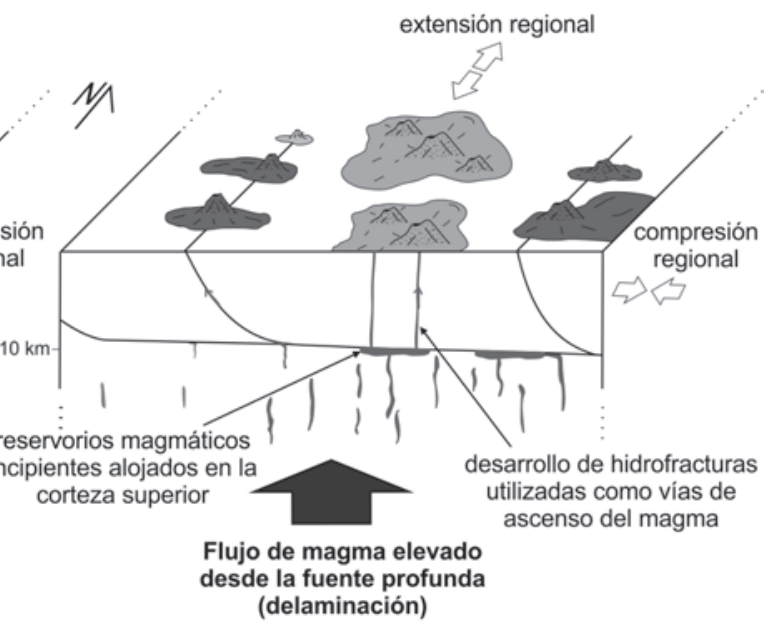

FIG. 11. Modelo conceptual esquemático donde se representan los rasgos fundamentales de los campos volcánicos (modificado de Báez et al., 2017): A. Control estructural del volcanismo monogenético por estructuras preexistentes (e.g., Pasto Ventura). B. Campo dominado por el aporte magmático generado en una fuente profunda relacionada con un proceso de delaminación (e.g., Antofagasta de la Sierra; Báez et al., 2017). Ver el texto para una mayor explicación. 


\subsection{Factores que controlan las variaciones en los estilos eruptivos y tipologías de volcanes}

\subsubsection{Estilos eruptivos explosivos-efusivos versus efusivos (conos de escoria versus domos)}

En la región de Pasto Ventura se reconocen estilos eruptivos mixtos explosivo-efusivo (e.g., estromboliano con efusión de lavas simultáneamente) que dieron lugar a los conos de escoria y estilos eruptivos solo efusivos que dieron lugar a los domos y coladas dómicas. En algunos casos, la actividad efusiva fue precedida por una fase explosiva debido a interacción agua/magma (domos precedidos por erupciones freatomagmáticas; Def), proceso que se discute en la siguiente sección. La ocurrencia de estilos eruptivos explosivos o efusivos se relaciona en gran medida con la capacidad del magma en ascenso de desgasificarse inhibiendo el proceso de fragmentación, lo que a su vez está controlado por una compleja interacción de factores que incluyen el contenido de volátiles inicial, la viscosidad y velocidad de ascenso del magma (Burgisser y Degruyter, 2015). Los magmas del área de estudio tienen ligeras variaciones geoquímicas, la mayor parte de los centros tienen composiciones andesíticas basálticas, sin embargo presentan una amplia diversidad en su composición mineralógica. Por un lado, los conos de escoria se caracterizan por una asociación mineral de fenocristales del tipo Ol-Cpx (en algunos casos con $\pm \mathrm{Pl}$ ) y composiciones ligeramente más básicas. Por otro lado, los domos tienen dos asociaciones minerales de fenocristales principales: $\mathrm{Cpx} \pm \mathrm{Ol}$ y $\mathrm{Amp} \pm \mathrm{Cpx}$, y composiciones ligeramente más ácidas. Esta variabilidad mineralógica en las andesitas y andesitas basálticas asociadas a ambientes de subducción es normalmente interpretada como variaciones de los parámetros intensivos preeruptivos de los magmas (e.g., Sisson y Grove, 1993; Moore y Carmichael, 1998; Maro, 2015; Maro y Caffe, 2016). En este sentido, es posible que los magmas con fases minerales anhidras ascendieran rápidamente desde un reservorio profundo, mientras que los magmas con anfíbol tuvieran etapas de estancamiento en la corteza media-superior donde sufrieron una significativa reducción de su temperatura (e.g., Presta y Caffe, 2014; Maro, 2015; Maro y Caffe, 2016). Los magmas con fenocristales de $\mathrm{Ol}+\mathrm{Cpx} \pm \mathrm{Pl}$ representarían una situación transicional donde la disminución de la temperatura permitió la estabilización de plagioclasa (e.g., Pichavant et al., 2002; Hamada y Fujii, 2008; Maro, 2015). De la misma manera los magmas con fenocristales de $\mathrm{Cpx} \pm \mathrm{Ol}$, con texturas de desequilibrio en los olivinos, o con fenocristales de $\mathrm{Ol}+\mathrm{Amp}$ evidenciarían la progresiva desestabilización del olivino y el clinopiroxeno, los cuales reaccionan con el fundido para formar anfíbol debido, fundamentalmente, a la disminución de la temperatura (e.g., Maro, 2015). Las ligeras variaciones geoquímicas entre los domos y los conos, acompañadas por un solapamiento de los valores de \#Mg (Apéndice tabla 4) y un comportamiento aleatorio de las relaciones isotópicas de ${ }^{87} \mathrm{Sr} /{ }^{86} \mathrm{Sr} y$ $\varepsilon \mathrm{Nd}$ (Murray et al., 2015), podrían explicarse por procesos de asimilación selectiva durante ascenso turbulento (ATA; Moorbath y Thompson, 1980), mecanismo ya propuesto para magmas máficos de la Puna (Guzmán et al., 2006; Maro et al., 2017b). La mayor o menor capacidad de los magmas máficos para atravesar la corteza se puede relacionar con el grado de interacción con fundidos félsicos en la corteza media, diferencias en la presión interna de los diques y/o variaciones en la geometría y cinemática de las estructuras tectónicas utilizadas como vías de ascenso. El estancamiento y enfriamiento de los magmas en la corteza media-superior se traduce en un aumento de su viscosidad y por ende en una disminución de su velocidad de ascenso final (Browne y Szramek, 2015). Tasas de ascenso bajas permiten la desgasificación pasiva del magma dando como resultado erupciones efusivas con formación de domos y coladas dómicas (Cashman et al., 2000). En contraste los magmas que ascendieron más rápidamente se desgasificaron de manera menos eficiente, conservando suficientes volátiles para fragmentarse cerca de la superficie y dinamizar erupciones explosivas de tipo estrombolianas que dieron lugar a la formación de los conos de escorias. Las bajas tasas de ascenso asociadas a la actividad efusiva de la región de Pasto Ventura están evidenciadas por los mayores valores modales y mayor tamaño de los microlitos en las muestras de domos respecto a la de los conos de escoria. Por otro lado, la ocurrencia de anfíboles con bordes de reacción o totalmente reemplazados por óxidos de hierro en los domos, también sugiere bajas tasas de ascenso (Rutherford, 2008).

\subsubsection{Variaciones en los estilos eruptivos durante la formación de los conos de escoria}

Algunos conos de escoria de la región de Pasto Ventura tienen evidencias de una fase inicial en su formación caracterizada por una actividad de tipo 
fisural con un estilo eruptivo de tipo hawaiano (facies $\mathrm{Sp}$ ). Considerando una morfología irregular para los diques que alimentan este tipo de erupciones fisurales, podemos inferir que el flujo de magma es más lento en las secciones más estrechas (Gonnermann y Taisne, 2015). En estos sectores la relación entre el transporte de calor por advección y el enfriamiento del magma por conducción es menor, resultando en un magma más frío, una viscosidad más alta y, por lo tanto, una disminución adicional del flujo que finalmente da lugar a la solidificación del magma contra las paredes del dique (Gonnermann y Taisne, 2015). En última instancia, este proceso puede dar como resultado la localización del flujo de magma en vías de tipo "conducto" donde se focaliza la actividad volcánica de tipo estromboliana que construyó el cuerpo principal de los conos de escoria. Esta transición de actividad fisural hacia una actividad más puntual ha sido observada en la evolución de conos de escoria recientes (e.g., Cono Navidad, Chile; Moreno y Gardeweg, 1989). La mayoría de los conos de escoria de la región de Pasto Ventura tienen coladas de lavas asociadas. Esta dualidad de estilos eruptivos (explosivo-efusivo) requiere que la segregación de la fase volátil ocurra en niveles poco profundos del conducto central (dentro del cono o justo por debajo del mismo) (Pioli et al., 2008). Esto permite que la fase más desgasificada del magma aproveche zonas de debilidad para moverse ya sea a través de diques laterales o generando nuevas bocas a lo largo del dique alimentador principal, dando lugar a la emisión de coladas de lava (Pioli et al., 2008; Valentine et al., 2006). Finalmente, los pulsos estrombolianos violentos probablemente coincidieron con períodos de mayor tasa de emisión (e.g., Báez et al., 2017).

\subsubsection{Actividad freatomagmática}

Un rasgo particular de la región de Pasto Ventura es el porcentaje alto de actividad freatomagmática (maares, anillos de tobas y actividad freatomagmática predómica) en comparación con otras agrupaciones de volcanes monogenéticos de la Puna Austral (Fig. 12). Esta característica podría ser resultado de diversos factores externos que favorecen la interacción aguamagma. Uno de ellos podría ser el cambio climático de la región durante la evolución de la agrupación de volcanes monogenéticos, en donde la interacción agua-magma podría responder a períodos de mayor humedad (e.g., Kereszturi et al., 2011). La falta de datos geocronológicos de todos los centros eruptivos de Pasto
Ventura hace imposible evaluar esta posibilidad. Sin embargo, el aumento significativo de los porcentajes de estructuras/depósitos freatomagmáticos solo en un área determinada de la Puna sugiere que existe un control de tipo geográfico. Pasto Ventura se ubica en el borde oriental del altiplano, en una región más húmeda respecto a otros agrupamientos de volcanes monogenéticos de la Puna Austral (Bianchi y Yáñez, 1992; Bianchi et al., 2005'; Fig. 12). Estas condiciones de mayor humedad en el borde oriental de los Andes Centrales persisten, al menos, desde el Mioceno tardío (Strecker et al., 2007). En este sentido, la posición geográfica de Pasto Ventura podría explicar mejor la abundancia de actividad freatomagmática sin necesidad de recurrir a variaciones climáticas regionales. $\mathrm{La}$ hidrofragmentación involucra la interacción física del magma con una fuente externa de agua en subsuelo o en superficie. Las erupciones freatomagmáticas resultan de la expansión volumétrica del agua que entra en contacto con el magma a alta temperatura generando la fragmentación del mismo (e.g., Morrissey et al., 2000), produciendo diferentes tipos de estructuras volcánicas como maares y anillos de tobas. Los maares excavan la superficie preeruptiva por lo que la zona de interacción agua-magma ocurre en el subsuelo y se asocia comúnmente a acuíferos por permeabilidad secundaria en roca de basamento (Lorenz, 2003) o a acuíferos profundos por permeabilidad primaria en rocas sedimentarias. Por otro lado, los anillos de tobas son estructuras positivas de acumulación en donde la interacción agua-magma ocurre cerca o en la superficie. El desarrollo de este tipo de estructuras se asocia a acuíferos superficiales por porosidad primaria en rocas sedimentarias y a cuerpos de aguas superficiales (Lorenz, 2003). Esta diferencia en los mecanismos de generación de estructuras volcánicas de tipo freatomagmáticas se ve reflejado en la región de Pasto Ventura. Por un lado, los maares se encuentran emplazados en bloques del basamento levantados por fallas donde la interacción agua-magma ocurrió en un acuífero profundo alojado en rocas de basamento (Figs. 13A, B). Esta interpretación es consistente con la abundancia de fragmentos líticos accidentales de basamento que se observan en los depósitos piroclásticos asociados a los maares. En contraste los anillos de tobas se encuentran emplazados en posiciones topográficas deprimidas rellenas de sedimentos poco consolidados (Fig. 13A) donde es factible la acumulación de cuerpos de agua y/o el desarrollo de acuíferos superficiales, por lo que se

'Bianchi, A.R.; Yáñez, C.E.; Acuña, L.R. 2005. Base de datos mensuales de precipitaciones del Noroeste Argentino: Proyecto Riesgo Agropecuario, Instituto Nacional de Tecnología Agropecuaria, Convenio Específico 3: p. 41. 


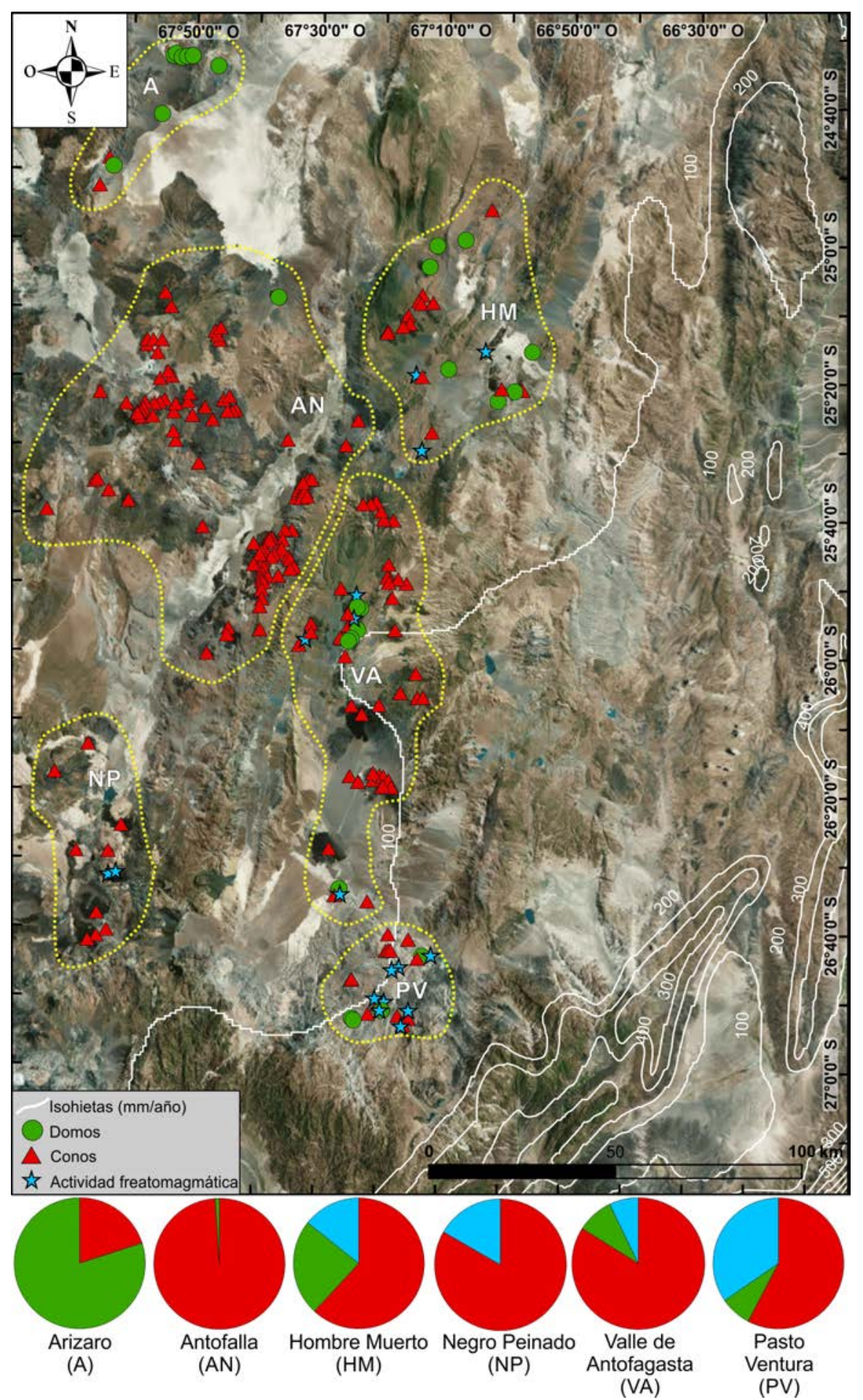

FIG. 12. Mapa de isohietas (precipitaciones medias anuales en mm/año) y centros volcánicos monogenéticos máficos de la Puna Austral clasificados en conos de escorias, domos y actividad freatomagmática. Nótese la abundancia de actividad freatomagmática en la región de Pasto Ventura en coincidencia con precipitaciones medias anuales más abundantes. Isohietas generadas a partir de datos tomados de Bianchi y Yáñez (1992). 
infiere que la interacción agua-magma ocurrió en o cerca de la superficie. Esta interpretación es consistente con la escasez de fragmentos líticos accidentales en los depósitos piroclásticos asociados a los anillos de tobas. Esta situación respecto a la topografía y al tipo de sustrato también se ve reflejada en los domos Def, a los cuales se asocia una etapa explosiva inicial de tipo freatomagmática relacionada con la interacción del magma en ascenso con cuerpos de agua poco profundos (Fig. 13B). Otro factor importante que controla la eficiencia de la interacción agua-magma es la velocidad de ascenso del magma, ya que si la misma es baja existe más tiempo para lograr el contacto entre las dos fases (e.g., Houghton et al., 2015). En este sentido, los fragmentos juveniles asociados a las estructuras freatomagmáticas en la región de Pasto Ventura tienen en general una composición más ácida, similar a la de los domos. Como se mencionó anteriormente estos rasgos composicionales condicionan la velocidad de ascenso final del magma. La interpretación de que la actividad freatomagmática se ve favorecida por velocidades de ascenso del magma más lentas está fuertemente respaldada por la ocurrencia de domos precedidos por erupciones freatomagmáticas (Def).

\section{Conclusiones}

Los volcanes monogenéticos de la región de Pasto Ventura se caracterizan por dos aspectos fundamentales: i. una baja densidad de centros eruptivos de pequeño volumen alineados con estructuras tectónicas regionales y ii. una importante variabilidad en los estilos eruptivos y tipología de estructuras volcánicas.

El primero de estos rasgos se explica por un flujo de magma limitado desde la fuente profunda y la utilización de estructuras tectónicas orientadas NE-SO (oblicuas a la dirección de compresión máxima)

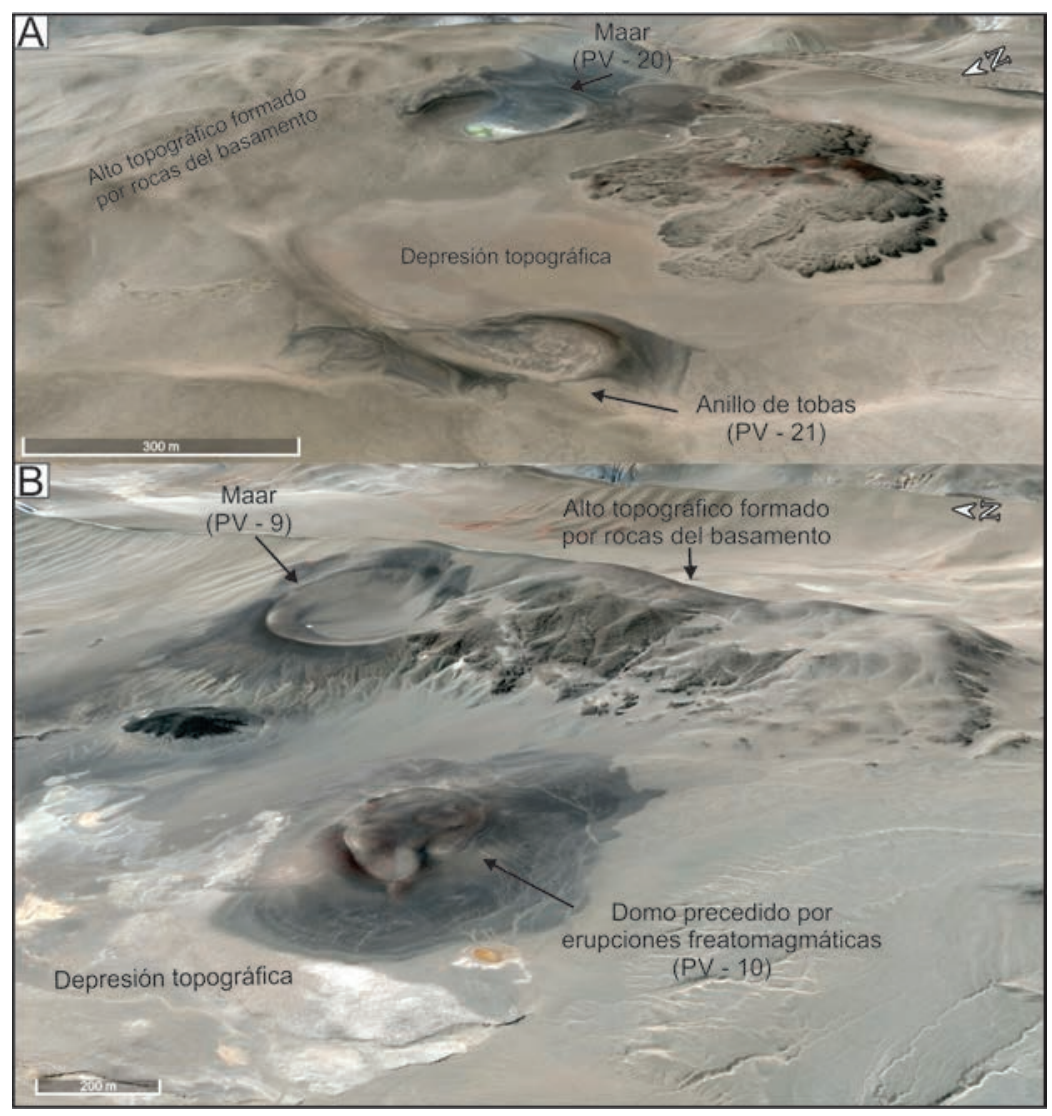

FIG. 13. A. Control de la topografía y del tipo de substrato en la ocurrencia de maares y anillos de tobas; B. Control de la topografía y del tipo de substrato en la ocurrencia de domos precedidos por erupciones freatomagmáticas (Def). 
favorables para el ascenso de pequeños volúmenes de magma a través de la corteza superior. El flujo limitado de magma de origen profundo respondería a una posición marginal de la región de Pasto Ventura respecto a la zona afectada por una importante delaminación litosférica o alternativamente a una posición sobre una región afectada por la remoción de un pequeño bloque litosférico.

Por otro lado, la variabilidad de estilos eruptivos y tipología de estructuras volcánicas responde a la compleja interacción de diferentes factores endógenos y exógenos. La ocurrencia de estilos eruptivos estrombolianos con formación de conos de escoria se asocia a magmas que ascendieron rápidamente desde un reservorio profundo y que se desgasificaron de manera poco eficiente, conservando suficientes volátiles para fragmentarse cerca de la superficie y dinamizar erupciones explosivas. En contraste, la actividad efusiva que da lugar a la formación de domos y coladas dómicas se asocia a magmas que tuvieron etapas de estancamiento en la corteza media-superior donde sufrieron una significativa reducción de su temperatura y aumento de su viscosidad. Ambos factores dan lugar a una tasa de ascenso baja, permitiendo la desgasificación pasiva del magma dando como resultado erupciones efusivas. Finalmente, la abundancia de actividad freatomagmática en la región de Pasto Ventura se explica fundamentalmente por su posición geográfica en el borde este de la Puna donde las precipitaciones promedio son mucho mayores que en su interior. Esta actividad freatomagmática está representada por maares, anillos de tobas y facies predómicas (asociados con una fase freatomagmática inicial). La ocurrencia de estas diferentes estructuras está controlada por las características del substrato y la profundidad a la cual ocurre la interacción agua- magma.

\section{Agradecimientos}

Este trabajo fue financiado por los proyectos GEOF 042014 "Estudio comparativo del vulcanismo bimodal reciente en las regiones oriental del Cinturón Volcánico Mexicano y la Puna Austral Argentina, génesis e implicaciones de riesgo volcánico" y CIUNSa No 1978/3. "Estudio del magmatismo bimodal del Neógeno-Reciente en el borde sudoriental de la Puna Austral". Los autores desean expresar su agradecimiento a la Dra. S. Guzmán y al Dr. W. Vivallo por sus valiosos comentarios y revisiones que ayudaron a mejorar sustancialmente la calidad del trabajo.

\section{Referencias}

Alaniz-Álvarez, S.A.; Nieto-Samaniego, Á.F.; Ferrari, L. 1998. Effect of strain rate in the distribution of monogenetic and polygenetic volcanism in the Transmexican volcanic belt. Geology 26: 591-594.

Allmendinger, R.W.; Strecker, M.; Eremchuk, J.E.; Francis, P. 1989. Neotectonic deformation of the southern Puna Plateau, northwestern Argentina. Journal of South American Earth Sciences 2 (2): 111-130.

Allmendinger, R.W.; Jordan, T.E.; Kay, S.M.; Isacks, B.L. 1997. The Evolution of the Altiplano-Puna Plateau of the Central Andes. Annual Review of Earth and Planetary Sciences 25 (1): 139-174. doi: 10.1146/ annurev.earth.25.1.139.

Alonso, R.; Viramonte, J.G.; Gutiérrez, R. 1984. Puna Austral-Bases para el subprovincialismo geológico de la Puna Argentina. In Congreso Geológico Argentino, No. 9, Actas 1: 43-63. San Carlos de Bariloche.

Astini, R.A.; Mors, R.A.; Gómez, F.J. 2018. Brechas y conglomerados epiclásticos dentro de los complejos volcánicos del sureste de la Puna y su relación con la fragmentación del antepaís. Revista de la Asociación Geológica Argentina 75 (1): 64-79.

Báez, W.; Carrasco Núñez, G.; Giordano, G.; Viramonte, J.G.; Chiodi, A. 2017. The polycyclic scoria cones of the Antofagasta de la Sierra basin, Southern Puna Plateau, Argentina. In Monogenetic Volcanism (Németh, K.; Carrasco-Núñez, G.; Aranda-Gómez, J.J.; Smith, I.E.M.; editors). The Geological Society, Special Publication 446 (1): 311-336. London.

Becchio, R.; Lucassen, F.; Franz, G.; Viramonte, J.; Wemmer, K. 1999. El basamento Paleozoico inferior del Noroeste de Argentina ( $\left.23^{\circ}-27^{\circ} \mathrm{S}\right)$-Metamorfismo y Geocronología. In Congreso Geológico Argentino, No. 14, Actas 1: 58-72. Salta.

Bianchi, A.R.; Yáñez, C.E. 1992. Las Precipitaciones en el Noroeste Argentino (Segunda Edición). Instituto Nacional de Tecnología Agropecuaria (INTA): 383 p. Salta.

Boltshauser, B. 2012. Ocurrencia y petrología de volcanes monogenéticos cuaternarios en el salar de Arizaro, Puna Austral. Trabajo Final (Inédito), Universidad Nacional de Córdoba, Facultad de Ciencias Exactas Físicas y Naturales: $104 \mathrm{p}$.

Browne, B.; Szramek, L. 2015. Rates of magma ascent and storage. In The encyclopedia of volcanoes, $2^{\text {nd }}$ edition (Sigurdsson, H.; Houghton, B.; McNutt, S.; Rymer, H.; Stix, J.; editors), Academic Press: 203-214. San Diego. 
Burgisser, A.; Degruyter, W. 2015. Magma ascent and degassing at shallow levels. In The encyclopedia of volcanoes, $2^{\text {nd }}$ edition (Sigurdsson, H.; Houghton, B.; McNutt, S.; Rymer, H.; Stix, J.; editors), Academic Press: 225-236. San Diego.

Bustos, E.; Báez, W.; Norini, G.; Arnosio, M.; de Silva, S. In press. The Geological and Structural Evolution of the Long-lived Miocene-Pleistocene La Hoyada Volcanic Complex in the Geodynamic Framework of the Central Andes, Argentina. Journal of Volcanology and Geothermal Research. doi: 10.1016/j. jvolgeores.2018.07.010

Calder, E.S.; Lavallée, Y.; Kendrick, J.E.; Bernstein, M. 2015. Lava dome eruptions. In The encyclopedia of volcanoes, $2^{\text {nd }}$ edition (Sigurdsson, H.; Houghton, B.; McNutt, S.; Rymer, H.; Stix, J.; editors), Academic Press: 343-362. San Diego.

Cas, R.A.; Wright, J.V. 1987. Volcanic successions, modern and ancient: A geological approach to processes, products, and successions. Allen and Unwin: 528 p. Londres.

Cashman, K.V.; Sturtevant, B.; Papale, P.; Navon, O. 2000. Magmatic fragmentation. In The encyclopedia of volcanoes (Sigurdsson, H.; Houghton, B.; Rymer, H.; Stix, J.; McNutt, S.; editors), Academic Press: 421430. San Diego.

Coira, B.; Kay, S.M.; Viramonte, J.G. 1993. Upper Cenozoic magmatic evolution of the Argentine Puna-a model for changing subduction geometry. International Geology Review 35: 677-720.

Connor, C.B.; Conway, F.M. 2000. Basaltic volcanic fields. In The encyclopedia of volcanoes (Sigurdsson, H.; Houghton, B.; Rymer, H.; Stix, J.; McNutt, S.; editors), Academic Press: 331-343. San Diego.

Corazzato, C.; Tibaldi, A. 2006. Fracture control on type, morphology and distribution of parasitic volcanic cones: An example from Mt. Etna, Italy. Journal of Volcanology and Geothermal Research 158 (1): 177-194.

Coronato, A.; Ercolano, B.; Corbella, H.; Tiberi, P. 2013. Glacial, fluvial and volcanic landscape evolution in the Laguna Potrok Aike maar area, Southern Patagonia, Argentina. Quaternary Science Reviews 71: 13-26.

Decelles, P.G.; Carrapa, B.; Horton, B.K.; McNabb, J.; Gehrels, G.E.; Boyd, J. 2015. The Miocene Arizaro Basin, central Andean hinterland: Response to partial lithosphere removal?. In Geodynamics of a Cordilleran Orogenic System: The Central Andes of Argentina and Northern Chile (DeCelles, P.G.; Ducea, M.N.; Carrapa, B.; Kapp, P.A.; editors), Geological Society of America Memoirs 212: 359-386. Virginia.
DeHoff, R.T.; Rhines, F.N. 1968. Quantitative microscopy. McGraw-Hill: 422 p. New York.

Déruelle, B. 1978. Calc-alkaline and shoshonitic lavas from five Andean volcanoes (between latitudes $21^{\circ} 45^{\prime}$ and $24^{\circ} 30^{\prime} \mathrm{S}$ ) and the distribution of the Plio-Quaternary volcanism of the south-central and southern Andes. Journal of Volcanology and Geothermal Research 3 (3-4): 281-298.

Deruelle, B. 1982. Petrology of the plio-quaternary volcanism of the South-Central and Meridional Andes. Journal of Volcanology and Geothermal Research 14: 77-124.

Déruelle, B. 1991. Petrology of Quaternary shoshonitic lavas of northwestern Argentina. Andean magmatism and its tectonic setting 265: 201-216.

Dóniz, J.; Romero, C.; Coello, E.; Guillén, C.; Sánchez, N.; García-Cacho, L.; García, A. 2008. Morphological and statistical characterisation of recent mafic volcanism on Tenerife (Canary Islands, Spain). Journal of Volcanology and Geothermal Research 173 (3): 185-195.

Drew, S.T.; Ducea, M.N.; Schoenbohm, L.M. 2009. Mafic volcanism on the Puna Plateau, NW Argentina: Implications for lithospheric composition and evolution with an emphasis on lithospheric foundering. Lithosphere 1 (5): 305-318.

Ducea, M.N.; Seclaman, A.C.; Murray, K.E.; Jianu, D.; Schoenbohm, L.M. 2013. Mantle-drip magmatism beneath the Altiplano-Puna plateau, Central Andes. Geology 41 (8): 915-918.

Göğüş, O.H.; Pysklywec, R.N. 2008. Near-surface diagnostics of dripping or delaminating lithosphere. Journal of Geophysical Research: Solid Earth 113: 1-11.

Gonnermann, H.M.; Manga, M. 2005. Flow banding in obsidian: A record of evolving textural heterogeneity during magma deformation. Earth and Planetary Science Letters 236 (1-2): 135-147. doi: 10.1016/j. eps1.2005.04.031.

Gonnermann, H.; Taisne, B. 2015. Magma transport in dikes. In The encyclopedia of volcanoes, $2^{\text {nd }}$ edition (Sigurdsson, H.; Houghton, B.; McNutt, S.; Rymer, H.; Stix, J.; editors), Academic Press: 215-224. San Diego.

Götze, H.J.; Krause, S. 2002. The Central Andean gravity high, a relic of an old subduction complex? Journal of South American Earth Sciences 14 (8): 799-811.

Grosse, P.; Guzmán, S.; Petrinovic, I. 2017. Volcanes compuestos cenozoicos del noroeste argentino. In Ciencias de la Tierra y Recursos Naturales del NOA (Muruaga, C.; Grosse, P.; editores). Congreso Geológico Argentino, No. 20, Asociación Geológica Argentina, Relatorio: 484-517. San Miguel de Tucumán. 
Guzmán, S.; Petrinovic, I.A.; Brod, J.A. 2006. Pleistocene mafic volcanoes in the Puna-Cordillera Oriental boundary, NW-Argentina. Journal of Volcanology and Geothermal Research 158: 51-69.

Guzmán, S.; Grosse, P.; Montero-López, C.; Hongn, F.; Pilger, R.; Petrinovic, I.; Seggiaro, R.; Aramayo, A. 2014. Spatial-temporal distribution of explosive volcanism in the $25-28^{\circ} \mathrm{S}$ segment of the Andean Central Volcanic Zone. Tectonophysics 636: 170-189.

Guzmán, S.; Grosse, P.; Martí, J.; Petrinovic, I.; Seggiaro, R. 2017a. Calderas cenozoicas argentinas de la Zona Volcánica Central de los Andes: procesos eruptivos y dinámica: una revisión. In Ciencias de la Tierra y Recursos Naturales del NOA (Muruaga, C.; Grosse, P.; editores). Congreso Geológico Argentino, No. 20, Asociación Geológica Argentina, Relatorio: 518-547. San Miguel de Tucumán.

Guzmán, S.; Strecker, M.R.; Martí, J.; Petrinovic, I.A.; Schildgen, T.F.; Grosse, P.; Montero López, C.; Neri, M.; Carniel, R.; Hongn, F.; Muruaga, C.; Sudo, M. 2017b. Construction and degradation of a broad volcanic massif: The Vicuña Pampa volcanic complex, southern Central Andes, NW Argentina. Geological Society of America Bulletin 129 (5-6): 750-766.

Guzmán, S.; Neri, M.; Carniel, R.; Martí, J.; Grosse, P.; Montero-López, C.; Geyer, A. 2017c. Remarkable variability of dyke features at the Vicuña Pampa Volcanic Complex, Southern Central Andes. Terra Nova 29: 224-232.

Hale, A.J.; Wadge, G. 2008. The transition from endogenous to exogenous growth of lava domes with the development of shear bands. Journal of Volcanology and Geothermal Research 171 (3): 237-257.

Hamada, M.; Fujii, T. 2008. Experimental constraints on the effects of pressure and $\mathrm{H}_{2} \mathrm{O}$ on the fractional crystallization of high-Mg island arc basalt. Contributions to Mineralogy and Petrology 155: 767-790.

Harris, A.J.; Rowland, S.K.; Villeneuve, N.; Thordarson, T. 2017. Pāhoehoe, "aa", and block lava: an illustrated history of the nomenclature. Bulletin of Volcanology 1 (79): 1-34.

Holm, R.F. 1987. Significance of agglutinate mounds on lava flows associated with monogenetic cones: An example at Sunset Crater, northern Arizona. Geological Society of America Bulletin 99 (3): 319-324.

Houghton, B.F.; Schmincke, H.U. 1989. Rothenberg scoria cone, East Eifel: a complex Strombolian and phreatomagmatic volcano. Bulletin of Volcanology 52 (1): 28-48.

Houghton, B.F.; White, J.D.; Van Eaton, A.R. 2015. Phreatomagmatic and related eruption styles. In The encyclopedia of volcanoes, $2^{\text {nd }}$ edition (Sigurdsson, H.; Houghton, B.; McNutt, S.; Rymer, H.; Stix, J.; editors), Academic Press: 537-552. San Diego.

Isacks, B.L. 1988. Uplift of the Central Andean Plateau and bending of the Bolivian Orocline. Journal of Geophysical Research, Solid Earth 93: 3211-3231.

Kay, S.M.; Coira, B.L. 2009. Shallowing and steepening subduction zones, continental lithospheric loss, magmatism, and crustal flow under the Central Andean Altiplano-Puna Plateau. In Backbone of the Americas: Shallow Subduction, Plateau Uplift, and Ridge and Terrane Collision (Kay, S.M.; Ramos, V.A.; Dickinson, W.R.; editors), Geological Society of America, Memoirs 204: 229-259. doi: 10.1130/2009.1204(11).

Kay, S.M.; Coira, B.; Viramonte, J.G. 1994. Young mafic back arc volcanic rocks as indicators of continental lithospheric delamination beneath the Argentine Puna Plateau, Central Andes. Journal of Geophysical Research 99: 24323-24339. doi: 10.1029/94JB00896.

Kereszturi, G.; Németh, K. 2012. Monogenetic basaltic volcanoes: genetic classification, growth, geomorphology and degradation. In Updates in Volcanology-New Advances in Understanding Volcanic Systems (Németh, K.; editor), Tech Open Access Publisher: 3-89. Rijeka.

Kereszturi, G.; Németh, K.; Csillag, G.; Balogh, K.; Kovács, J. 2011. The role of external environmental factors in changing eruption styles of monogenetic volcanoes in a Mio/Pleistocene continental volcanic field in western Hungary. Journal of Volcanology and Geothermal Research 201 (1): 227-240.

Knox, W.J.; Kay, S.M.; Coira, B. 1989. Geochemical evidence on the origin of Quaternary basaltic andesites of the Puna, northwestern Argentina. Revista de la Asociación Geológica Argentina 44: 194-206.

Krallmann, A. 1994. Petrographische und geochemische Untersuchungen an jungen, basischen Vulkaniten im Bereich des Calama-Olacapato-El Toro-Lineamentes östlich der Vulkankette, NW-Argentinien. Geologisches Institut der Technische Universitat of Clausthal Zellerfeld: 160 p. Clausthal-Zellerfeld.

Le Corvec, N.; Spörli, K.B.; Rowland, J.; Lindsay, J. 2013. Spatial distribution and alignments of volcanic centers: Clues to the formation of monogenetic volcanic fields. Earth-Science Reviews 124: 96-114.

Lesti, C.; Giordano, G.; Salvini, F.; Cas, R. 2008. Volcano tectonic setting of the intraplate, Pliocene-Holocene, Newer Volcanic Province (southeast Australia): role of crustal fracture zones. Journal of Geophysical Research 113: 1978-2012. doi: 10.1029/2007JB005110. 
Le Bas, M.J.; Le Maitre, R.W.; Streckeisen, A.; Zanettin, B. 1986. A chemical classification of volcanic rocks based on the total alkali-silica diagram. Journal of Petrology 27 (3): 745-750. doi: 10.1093/petrology/27.3.745.

Liu, J.G.; Mason, P.J. 2009. Essential Image Processing and GIS for Remote Sensing. John Wiley and Sons Ltd.: 460 p. London.

Lorenz, V. 1987. Phreatomagmatism and its relevance. Chemical Geology 62: 149-156.

Lorenz, V. 2003. Maar-diatreme volcanoes, their formation, and their setting in hard-rock or soft-rock environments. Geolines Journal of the Geological Institute of AS Czech Republic 15: 72-83.

Lucassen, F.; Becchio, R. 2003. Timing of high grade metamorphism: Early Paleozoic U-Pb formation ages of titanite indicate long-standing high-T conditions at the western margin of Gondwana (Argentina, 26$29^{\circ}$ S). Journal of Metamorphic Geology 21: 649-662.

Maro, G. 2015. Modelo eruptivo y petrogénesis del volcanismo monogenético neógeno de Puna norte. Tesis Doctoral (Inédito), Universidad Nacional de Salta: 409 p. Argentina.

Maro, G.; Caffe, P.J. 2016. The Cerro Bitiche Andesitic Field: petrological diversity and implications for magmatic evolution of mafic volcanic centers from the northern Puna. Bulletin of Volcanology 78 (7): 1-18.

Maro, G.; Caffe, P.J.; Báez, W. 2017a. Volcanismo monogenético máfico cenozoico de la Puna.85432 In Ciencias de la Tierra y Recursos Naturales del NOA (Muruaga, C.; Grosse, P.; editores). Congreso Geológico Argentino, No. 20, Asociación Geológica Argentina, Relatorio: 548-577. San Miguel de Tucumán.

Maro, G.; Caffe, P.J.; Romer, R.L.; Trumbull, R.B. 2017 b. Neogene mafic magmatism in the northern Puna Plateau, Argentina: Generation and evolution of a back-arc volcanic suite. Journal of Petrology 58: 1591-1618. doi: 10.1093/petrology/egx066.

Marrett, R.; Emerman, S.H. 1992. The relations between faulting and mafic magmatism in the AltiplanoPuna plateau (central Andes). Earth and Planetary Science Letters 112: 53-59. doi: 10.1016/0012-821X (92)90006-H.

Montero López, M.C. 2009. Estructura y magmatismo neógeno-cuaternarios en la sierra de San Buenaventura (Catamarca): su vinculación con la terminación austral de la Puna. Tesis Doctoral (Inédito), Facultad de Ciencias Naturales, Universidad Nacional de Salta: 255 p.

Montero López, M.C.; Hongn, F.; Marrett, R.; Seggiaro, R.; Strecker, M.; Sudo, M. 2010. Late Miocene-Pliocene onset of $\mathrm{N}-\mathrm{S}$ extension along the southern margin of the Central
Andean Puna plateau from magmatic, geochronological and structural evidences. Tectonophysics 494: 48-63. doi: 10.1016/j.tecto.2010.08.010.

Moorbath, S.; Thompson, R.N. 1980. Strontium isotope geochemistry and petrogenesis of the early tertiary lava pile of the Isle of Skye, Scotland, and other basic rocks of the British tertiary province: An example of magma-crust interaction. Journal of Petrology 21 (2): 295-321.

Moore, G.M.; Carmichael, I.S.E. 1998. The hydrous phase equilibria (to $3 \mathrm{kbar}$ ) of an andesite and basaltic andesite from Western Mexico: Constraints on water content and conditions of phenocryst growth. Contributions to Mineralogy and Petrology 130: 304-319.

Moreno, H.; Gardeweg, M.C. 1989. La erupción reciente en el complejo volcánico Lonquimay (Diciembre 1988), Andes del Sur. Andean Geology 16: 93-117. doi: 10.5027/andgeoV16n1-a06.

Morrissey, M.; Zimanowski, B.; Wohletz, K.; Buettner, R. 2000. Phreatomagmatic fragmentation. In The encyclopedia of volcanoes (Sigurdsson, H.; Houghton, B.; Rymer, H.; Stix, J.; McNutt, S.; editors), Academic Press: 431-445. San Diego.

Murray, K.E.; Ducea, M.N.; Schoenbohm, L. 2015. Foundering-driven lithospheric melting: the source of central Andean mafic lavas on the Puna Plateau $\left(22^{\circ} \mathrm{S}-27^{\circ} \mathrm{S}\right)$. In Geodynamics of a Cordilleran Orogenic System: The Central Andes of Argentina and Northern Chile (DeCelles, P.G.; Ducea, M.N.; Carrapa, B.; Kapp, P.A.; editors), Geological Society of America Memoirs 212: 139-166. Virginia.

Németh, K. 2010. Monogenetic volcanic fields: origin, sedimentary record, and relationship with polygenetic volcanism. In What is a Volcano? (Cañon-Tapia, E.; Szakács, A.; editors), Geological Society of America, Special Papers 470: 43-66. doi: 10.1130/ 2010.2470(04).

Németh, K.; Kereszturi, G. 2015. Monogenetic volcanism: personal views and discussion. International Journal of Earth Sciences 104: 2131-2146. doi: 10.1007/ s00531-015-1243-6.

Pardo, N.; Macías, J.L.; Giordano, G.; Cianfarra, P.; Avellán, D.R.; Bellatreccia, F. 2009. The 1245 yr BP Asososca maar eruption: the youngest event along the Nejapa-Miraflores volcanic fault, Western Managua, Nicaragua. Journal of Volcanology and Geothermal Research 184: 292-312. doi: 10.1016/j. jvolgeores.2009.04.006.

Petrinovic, I.A.; Grosse, P.; Guzmán, S.; Caffe, P. 2017. Evolución del volcanismo Cenozoico en la Puna 
Argentina. In Ciencias de la Tierra y Recursos Naturales del NOA(Muruaga, C.; Grosse, P.; editores). Congreso Geológico Argentino, No. 20. Asociación Geológica Argentina, Relatorio: 469-483. San Miguel de Tucumán.

Pichavant, M.; Mysen, B.O.; Macdonald, R. 2002. Source and $\mathrm{H}_{2} \mathrm{O}$ content of high-MgO magmas in island arc settings: an experimental study of a primitive calcalkaline basalt from St. Vincent, Lesser Antilles arc. Geochimica et Cosmochimica, Acta 66: 2193-2209.

Pioli, L.; Erlund, E.; Johnson, E.; Cashman, K.; Wallace, P.; Rosi, M.; Granados, H.D. 2008. Explosive dynamics of violent Strombolian eruptions: the eruption of Parícutin Volcano 1943-1952 (Mexico). Earth and Planetary Science Letters 271 (1): 359-368.

Presta, J.F.; Caffe, P.J. 2014. Historia eruptiva de los volcanes

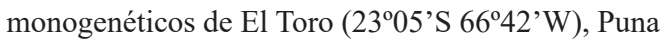
norte, Argentina. Andean Geology 41 (1): 142-173. doi: 10.5027/andgeoV41n1-a06.

Riller, U.; Oncken, O. 2003. Growth of the Central Andean Plateau by Tectonic Segmentation Is Controlled by the Gradient in Crustal Shortening. The Journal of Geology 111: 367-384.

Risse, A.; Trumbull, R.B.; Coira, B.; Kay, S.M.; Van Den Bogaard, P. 2008. ${ }^{40} \mathrm{Ar} /{ }^{39} \mathrm{Ar}$ geochronology of mafic volcanism in the back-arc region of the southern Puna plateau, Argentina. Journal of South American Earth Science 26: 1-15.

Risse, A.; Trumbull, R.B.; Kay, S.M.; Coira, B.; Romer, R.L. 2013. Multi-stage Evolution of Late Neogene Mantlederived Magmas from the Central Andes Back-arc in the Southern Puna Plateau of Argentina. Journal of Petrology 54 (10): 1963-1995.

Roberts, N.; Reed, J.M. 2009. Lakes, wetlands, and Holocene environmental change. In The physical geography of the Mediterranean (Woodward, J.; editor). Oxford regional environments series, Oxford University Press: 255-286.

Rossello, E. 1980. Nuevo Complejo Volcánico Vicuña Pampa, departamento Belén, provincia de Catamarca. Revista de la Asociación Geológica Argentina 35 (3): 436-438.

Ruiz Huidobro, O. 1975. Descripción geológica de la Hoja geológica 12c, Laguna Helada. Provincia de Catamarca: Carta geológico-económica de la República Argentina, escala 1:200.000. Servicio Geológico Nacional, Boletín 146: 54 p. Buenos Aires.

Russo, Y.B. 2010. Caracterización y clasificación de las unidades geomorfológicas del ambiente volcánico de la cuenca media del río Punilla. Antofagasta de la sierra-Catamarca. Memoria de Título (Inédito).
Universidad Nacional de Catamarca, Facultad de Tecnología y Ciencias Aplicadas: 208 p.

Rutherford, M.J. 2008. Magma ascent rates. Reviews in Mineralogy and Geochemistry 69 (1): 241-271.

Schoenbohm, L.M.; Carrapa, B. 2015. Miocene-Pliocene shortening, extension and mafic magmatism support small-scale lithospheric foundering in the central Andes, NW Argentina. In Geodynamics of a Cordilleran Orogenic System: The Central Andes of Argentina and Northern Chile (DeCelles, P.G.; Ducea, M.N.; Carrapa, B.; Kapp, P.A.; editors), Geological Society of America Memoirs 212: 167-180. Virginia.

Seggiaro, R.; Hongn, F.; Folguera, A.; Clavero, J. 2006. Hoja Geológica 2769-II Paso de San Francisco, Provincia de Catamarca. Programa Nacional de Cartas Geológicas, escala 1:250.000. Servicio Geológico Minero de Argentina, Boletín 294: 76 p. Buenos Aires.

Sisson, T. W.; Grove, T.L. 1993. Experimental investigations of the role of $\mathrm{H}_{2} \mathrm{O}$ in calc-alkaline differentiation and subduction zone magmatism. Contributions to Mineralogy and Petrology 11 (2): 143-166.

Strecker, M.R.; Alonso, R.N.; Bookhagen, B.; Carrapa, B.; Hilley, G.E.; Sobel, E.R.; Trauth, M.H. 2007. Tectonics and climate of the southern central Andes. Annual Review of Earth and Planetary Sciences 35: 747-787.

Suzaño, N.; Becchio, R.; Sola, A.; Fuentes, G.; Ortiz, A. 2014. Dominios de basamento del Paleozoico Inferior en la Sierra de El Peñón, Puna Austral, Provincia de Catamarca. In Congreso Geológico Argentino, No. 19, Actas: CD-Rom S21-57. San Miguel de Tucumán.

Turner, J.C. 1972. Puna (Leanza, A.; editor). In Simposio de Geología Regional Argentina, No. 1, Academia Nacional de Ciencias: 91-116. Córdoba.

Valentine, G.A.; Gregg, T.K.P. 2008. Continental basaltic volcanoes-processes and problems. Journal of Volcanology and Geothermal Research 177 (4): 857-873.

Valentine, G.A.; Connor, C.B. 2015. Basaltic Volcanic Fields. In The encyclopedia of volcanoes, $2^{\text {nd }}$ edition (Sigurdsson, H.; Houghton, B.; McNutt, S.; Rymer, H.; Stix, J.; editors), Academic Press: 215-224. San Diego.

Valentine, G.A.; Perry, F.V.; Krier, D.; Keating, G.N.; Kelley, R.E.; Cogbill, A.H. 2006. Small-volume basaltic volcanoes: Eruptive products and processes, and posteruptive geomorphic evolution in Crater Flat (Pleistocene), southern Nevada. Geological Society of America Bulletin 118 (11-12): 1313-1330.

Vespermann, D.; Schmincke, H.U. 2000. Scoria cones and tuff rings. In The encyclopedia of volcanoes (Sigurdsson, H.; Houghton, B.; Rymer, H.; Stix, J.; 
McNutt, S.; editors), Academic Press: 683-694. San Diego.

Viramonte, J.G.; Petrinovic, I. 1999. La caldera Culampajá. Una nueva caldera basáltica de la Puna Austral. In Congreso Geológico Argentino, No. 14, Actas 2: 235. Salta.

Viramonte, J.G.; Galliski, M.A.; Araña Saavedra, V.; Aparicio, A.; García Cucho, L.; Martín Escorza, C. 1984. El finivulcanismo máfico de la depresión de Arizaro, provincia de Salta. In Congreso Geológico Argentino, No. 9, Actas 3: 234-251. San Carlos de Bariloche.

Viramonte, J.G.; Heit, B.; Báez, W. 2010. The role of the central Andes gravity high in the control of the type and distribution of the back arc monogenetic basic volcanism cluster in the southern central Andes. In Meeting of the Americas, Eos Transactions of the American Geophysical Union, Meeting of the Americas Supplement 91, Abstract V23A-01. Foz do Iguazu.

Whitney, D.L.; Evans, B.W. 2010. Abbreviations for names of rock-forming minerals. American mineralogist 95 (1): 185-187.
Wohletz, K.H.; Sheridan, M.F. 1983. Hydrovolcanic explosions; II, Evolution of basaltic tuff rings and tuff cones. American Journal of Science 283 (5): 385-413.

Wood, C.A. 1980. Morphometric analysis of cinder cone degradation. Journal of Volcanology and Geothermal Research 8 (2): 137-160.

Wright, H.M.; Cashman, K.V.; Rosi, M.; Cioni, R. 2007. Breadcrust bombs as indicators of Vulcanian eruption dynamics at Guagua Pichincha volcano, Ecuador. Bulletin of Volcanology 69 (3): 281-300.

Zhou, R.; Schoenbohm, L.M. 2015. Late Miocene uppercrustal deformation within the interior of the southern Puna Plateau, central Andes. Lithosphere 7: 336-352.

Zhou, R.; Schoenbohm, L.M.; Cosca, M. 2013. Recent, slow normal and strike-slip faulting in the Pasto Ventura region of the southern Puna Plateau, NW Argentina. Tectonics 32: 19-33. doi: 10.1029/2012TC003189.

Zhou, R.; Schoenbohm, L.M.; Sobel, E.R.; Carrapa, B.; Davis, D.W. 2016. Sedimentary record of regional deformation and dynamics of the thick-skinned southern Puna Plateau, Central Andes (26-27 S). Earth and Planetary Science Letters 433: 317-325.

Manuscript received: July 17, 2017; revised/accepted: October 22, 2018; available online: February 04, 2019. 


\section{Apéndice}

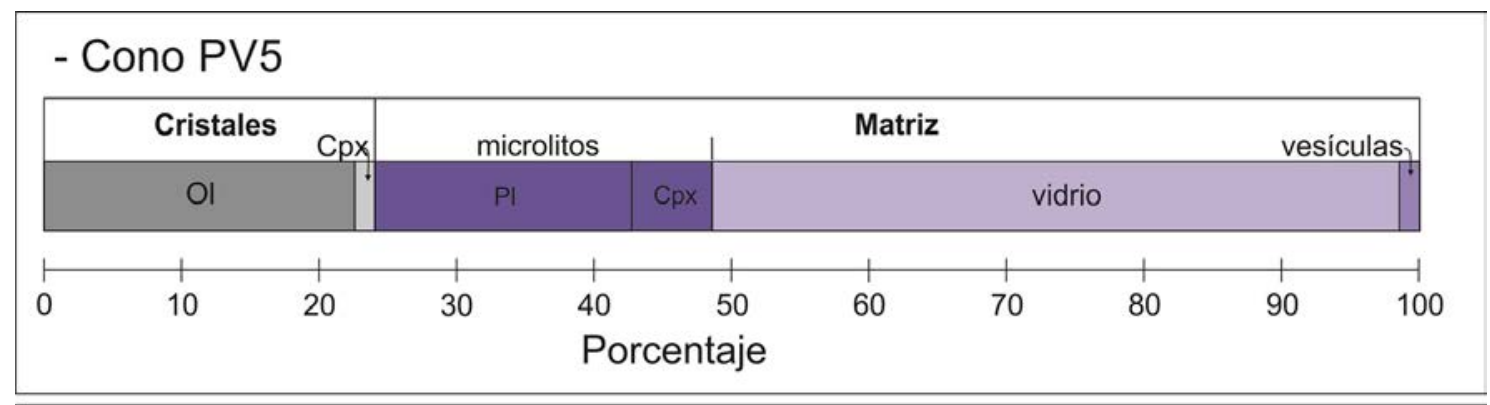

\section{- Cono Pv6}

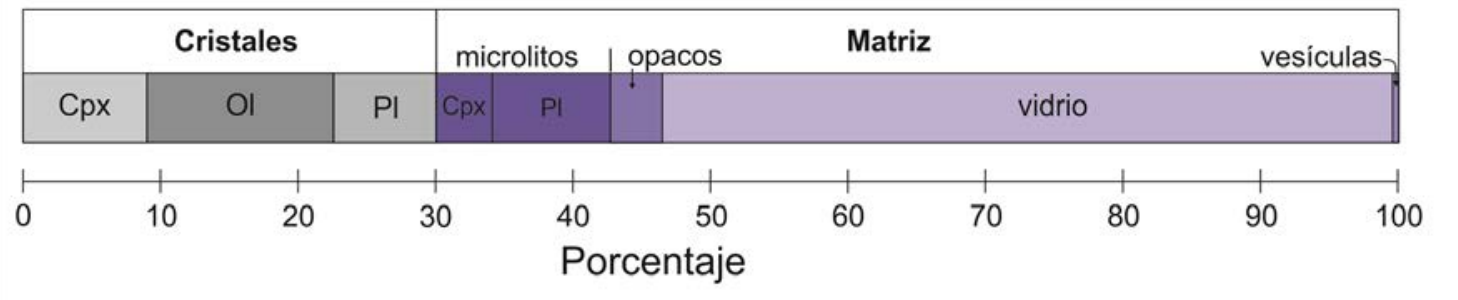

\section{- Domo PV1}

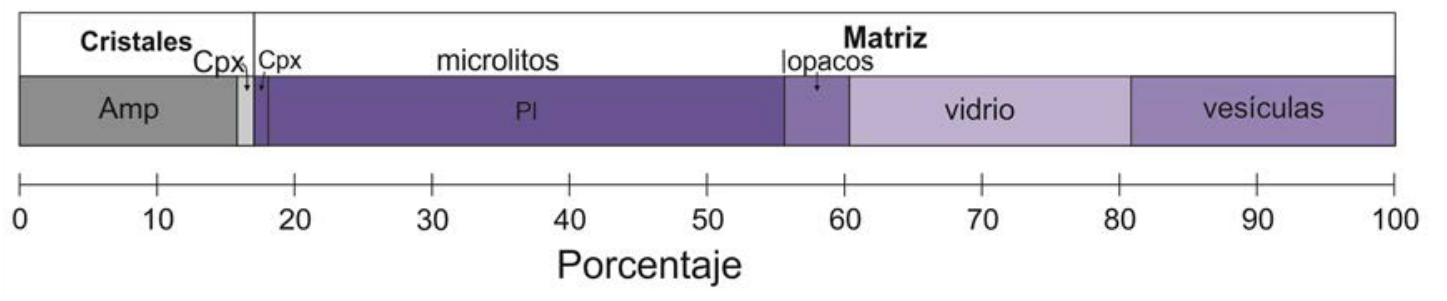

\section{- Domo PV10}

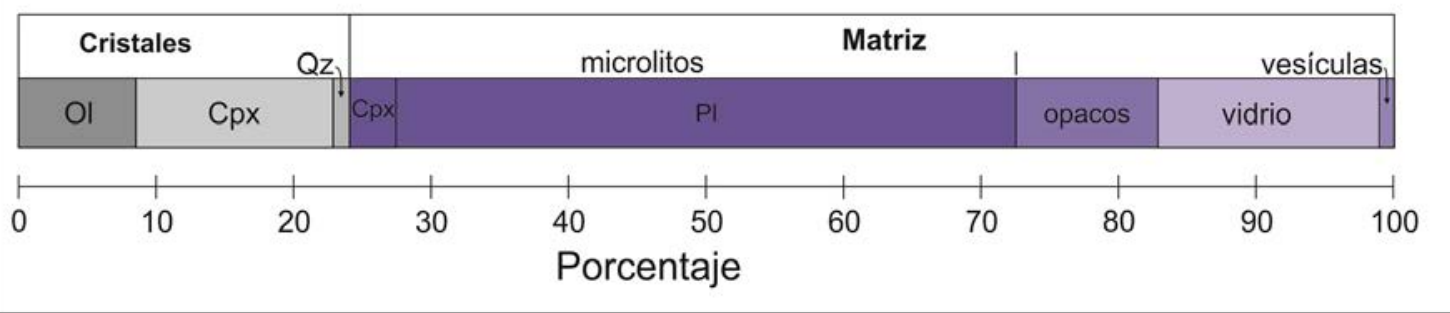

FIG. 1. Análisis modal de muestras representativas de conos de escoria y domos. Ol: olivino; Qz: cuarzo; Cpx: clinopiroxeno; Amp: anfíbol; PI: plagioclasa. 
TABLA 1. PARÁMETROS MORFOMÉTRICOS OBTENIDOS PARA LOS CONOS DE ESCORIA DE LA REGIÓN DE PASTO VENTURA SEGÚN WOOD (1980); CORAZZATO Y TIBALDI (2006) Y DÓNIZ ET AL. (2008). (*)

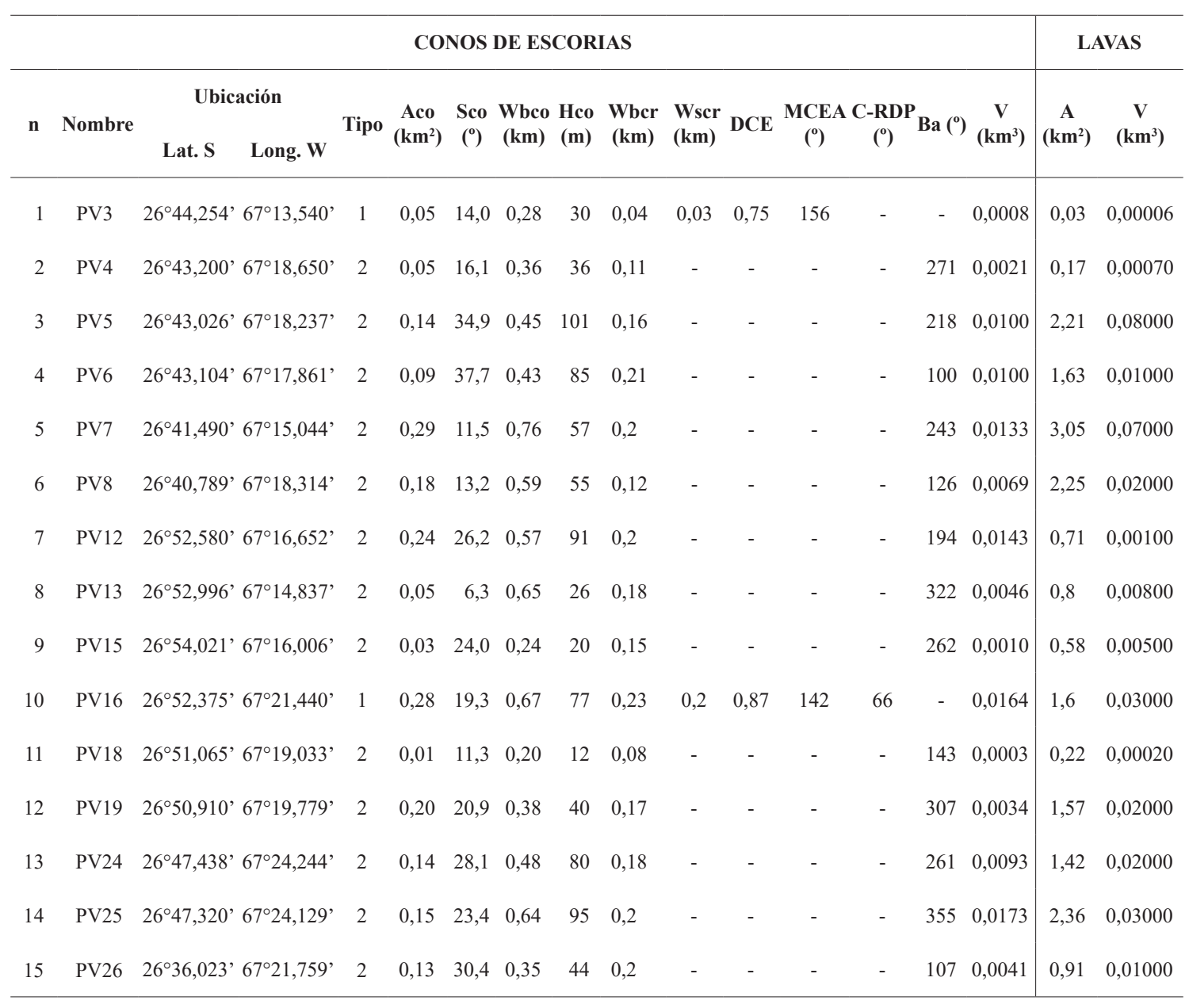

(*) Tipo 1: conos completos; Tipo 2: conos aportillados. Área basal (Aco), pendiente (Sco), diámetro de la base (Wbco), altura (Hco), diámetro máximo del cráter (Wbcr), ancho mínimo del cráter (Wscr), grado de elipticidad (DCE), azimut de máxima elongación (MCEA), azimut de puntos deprimidos del borde de cráter (C-RDP), azimut de aportillamiento (Ba), volumen (V), área (A). 
TABLA 2. PARÁMETROS MORFOMÉTRICOS OBTENIDOS PARA LOS DOMOS DE LA REGIÓN DE PASTO VENTURA. (*)

\begin{tabular}{|c|c|c|c|c|c|c|c|c|c|c|c|}
\hline \multicolumn{12}{|c|}{ DOMOS } \\
\hline \multirow{2}{*}{ n } & \multirow{2}{*}{ Nombre } & \multicolumn{2}{|c|}{ Ubicación } & \multirow{2}{*}{ Tipo } & \multirow{2}{*}{$\underset{\left(\mathbf{k m}^{2}\right)}{A}$} & \multirow{2}{*}{$\begin{array}{c}\text { Ls } \\
(\mathbf{k m})\end{array}$} & \multirow{2}{*}{$\begin{array}{c}\text { Ws } \\
(\mathbf{k m})\end{array}$} & \multirow{2}{*}{$\mathbf{E}$} & \multirow{2}{*}{ Hs (m) } & \multirow{2}{*}{$\mathrm{V}\left(\mathrm{km}^{3}\right)$} & \multirow{2}{*}{ e $\left(^{\circ}\right)$} \\
\hline & & Lat. $S$ & Long. W & & & & & & & & \\
\hline 1 & PV 1 & $26^{\circ} 43,913^{\prime}$ & $67^{\circ} 12,781^{\prime}$ & Dnef & 1,12 & 1,46 & 0,99 & 0,67 & 122 & 0,13 & 32 \\
\hline 2 & PV 2 & $26^{\circ} 43,789^{\prime}$ & $67^{\circ} 12,118^{\prime}$ & Def & 0,45 & 0,85 & 0,79 & 0,92 & 50 & 0,02 & 31 \\
\hline 3 & PV 10 & $26^{\circ} 45,685^{\prime}$ & $67^{\circ} 17,442^{\prime}$ & Def & 0,11 & 0,52 & 0,35 & 0,67 & 41 & 0,004 & 89 \\
\hline 4 & PV 11 & $26^{\circ} 51,766^{\prime}$ & $67^{\circ} 14,852^{\prime}$ & Def & 1,04 & 1,41 & 0,95 & 0,67 & 87 & 0,09 & 58 \\
\hline 5 & PV 22 & $26^{\circ} 52,962^{\prime}$ & $67^{\circ} 24,027^{\prime}$ & Dnef & 1,44 & 1,85 & 0,97 & 0,52 & 136 & 0,19 & 53 \\
\hline 6 & PV 23 & $26^{\circ} 53,275^{\prime}$ & $67^{\circ} 23,763^{\prime}$ & Def & 0,21 & 0,62 & 0,59 & 0,95 & 92 & 0,019 & 52 \\
\hline
\end{tabular}

(*) Def: domos precedidos por erupciones freatomagmáticas; Dnef: domos no precedidos por erupciones freatomagmáticas. Área (A), elongación máxima $(\mathbf{L s})$, ancho $(\mathbf{W s})$, elipticidad $(\mathbf{E}=\mathbf{W} \mathbf{s} / \mathbf{L s})$, altura $(\mathbf{H s})$, volumen $(\mathbf{V})$, azimut del eje de máxima elongación $(\mathbf{e})$.

\section{TABLA 3. PARÁMETROS MORFOMÉTRICOS (MODIFICADO DE WOHLETZ Y SHERIDAN, 1983) OBTENIDOS PARA LAS ESTRUCTURAS FREATOMAGMÁTICAS DE LA REGIÓN DE PASTO VENTURA. (*)}

\begin{tabular}{|c|c|c|c|c|c|c|c|c|c|}
\hline \multicolumn{10}{|c|}{ ESTRUCTURAS FREATOMAGMÁTICAS } \\
\hline \multirow{2}{*}{ n } & \multirow{2}{*}{ Nombre } & \multicolumn{2}{|c|}{ Ubicación } & \multirow{2}{*}{ Tipo } & \multirow{2}{*}{$\begin{array}{l}\text { Rpy } \\
(\mathbf{k m})\end{array}$} & \multirow{2}{*}{$\begin{array}{c}\text { Apy } \\
\left(\mathbf{k m}^{2}\right)\end{array}$} & \multirow{2}{*}{$\begin{array}{c}\text { Dm } \\
(\mathrm{km})\end{array}$} & \multirow{2}{*}{$\begin{array}{c}\mathrm{Hm} \\
(\mathrm{km})\end{array}$} & \multirow{2}{*}{ H/D } \\
\hline & & Lat. $S$ & Long. W & & & & & & \\
\hline 1 & PV 9 & $26^{\circ} 45,426^{\prime}$ & $67^{\circ} 16,461^{\prime}$ & maar & 0,41 & 0,47 & 0,63 & 0,04 & 0,063 \\
\hline 2 & PV 14 & $26^{\circ} 53,901^{\prime}$ & $67^{\circ} 15,728^{\prime}$ & anillos de tobas & 0,75 & 1,11 & 0,35 & 0,01 & 0,029 \\
\hline 3 & PV 17 & $26^{\circ} 51,739^{\prime}$ & $67^{\circ} 19,486^{\prime}$ & anillos de tobas & 0,19 & 0,09 & 0,14 & 0,004 & 0,029 \\
\hline 4 & PV 20 & $26^{\circ} 50,482^{\prime}$ & $67^{\circ} 18,839^{\prime}$ & maar & 0,69 & 1,03 & 0,74 & 0,08 & 0,108 \\
\hline 5 & PV 21 & $26^{\circ} 49,988^{\prime}$ & $67^{\circ} 20,338^{\prime}$ & anillos de tobas & 0,29 & 0,27 & 0,53 & 0,014 & 0,026 \\
\hline
\end{tabular}

(*) Distancia máxima alcanzada por los depósitos desde el centro emisor (Rpy), área de los depósitos piroclásticos (Apy), diámetro de la estructura $(\mathbf{D m})$, altura $(\mathbf{H m})$, relación profundidad/diámetro $(\mathbf{H} / \mathbf{D})$. 
TABLA 4. ANÁLISIS GEOQUÍMICOS DE ELEMENTOS MAYORES EN ROCA TOTAL (FLUORESCENCIA DE RAYOS X).

\begin{tabular}{|c|c|c|c|c|c|c|c|c|c|c|c|c|c|c|c|c|c|}
\hline \multirow{2}{*}{ Edificio } & \multicolumn{2}{|c|}{ Muestra } & \multirow{2}{*}{ Tipo } & \multirow{2}{*}{$\mathrm{SiO}_{2}$} & \multirow{2}{*}{$\mathrm{TiO}_{2}$} & \multirow{2}{*}{$\mathrm{Al}_{2} \mathrm{O}_{3}$} & \multirow{2}{*}{$\mathrm{FeO}^{*}$} & \multirow{2}{*}{ MnO } & \multirow{2}{*}{ MgO } & \multirow{2}{*}{$\mathrm{CaO}$} & \multirow{2}{*}{$\mathrm{Na}_{2} \mathrm{O}$} & \multirow{2}{*}{$\mathbf{K}_{2} \mathbf{O}$} & \multirow{2}{*}{$\mathbf{P}_{2} \mathbf{O}_{5}$} & \multirow{2}{*}{ LOI } & \multirow{2}{*}{ Total } & \multirow{2}{*}{ \#Mg } & \multirow{2}{*}{ Fuente } \\
\hline & Lat. S & Long. W & & & & & & & & & & & & & & & \\
\hline PV 1 & $26^{\circ} 43,91$ & ' $67^{\circ} 12,781^{\prime}$ & D & 54,45 & 1,05 & 14,96 & 6,18 & 0,11 & 5,84 & 8,03 & 3,68 & 2,20 & 0,48 & 1,87 & 98,85 & 63 & $\mathrm{~b}$ \\
\hline PV 2 & $26^{\circ} 43,740^{\prime}$ & ' $67^{\circ} 12,298^{\prime}$ & $\mathrm{D}$ & 51,69 & 1,05 & 14,65 & 6,48 & 0,11 & 6,38 & 8,59 & 3,39 & 1,92 & 0,39 & 2,62 & 97,27 & 64 & $\mathrm{~b}$ \\
\hline PV 2 & $26^{\circ} 43,788^{\prime}$ & ' $67^{\circ} 12,118^{\prime}$ & $\mathrm{D}$ & 54,97 & 0,90 & 15,17 & 6,91 & 0,11 & 6,63 & 7,59 & 3,58 & 2,06 & 0,40 & 0,71 & 99,02 & 63 & $\mathrm{a}$ \\
\hline PV 2 & $26^{\circ} 43,902^{\prime}$ & ' $67^{\circ} 11,755^{\prime}$ & D & 54,79 & 0,88 & 14,92 & 6,87 & 0,14 & 6,48 & 7,73 & 3,49 & 2,05 & 0,41 & 1,45 & 99,22 & 63 & $\mathrm{a}$ \\
\hline PV 3 & $26^{\circ} 44,292^{\prime}$ & $' 67^{\circ} 13,488^{\prime}$ & CE & 53,15 & 1,09 & 15,07 & 7,29 & 0,12 & 7,00 & 8,10 & 3,29 & 1,95 & 0,34 & 1,44 & 97,41 & 63 & $\mathrm{c}$ \\
\hline PV 5 & $26^{\circ} 43,800^{\prime}$ & ' $67^{\circ} 18,000^{\prime}$ & $\mathrm{CE}$ & 50,61 & 1,16 & 15,43 & 7,61 & 0,11 & 7,65 & 10,64 & 3,34 & 1,52 & - & - & 98,03 & 64 & d \\
\hline PV 6 & $26^{\circ} 43,716^{\prime}$ & ' $67^{\circ} 16,854^{\prime}$ & $\mathrm{CE}$ & 52,23 & 1,15 & 15,70 & 7,77 & 0,13 & 7,40 & 8,37 & 3,46 & 1,77 & 0,35 & 1,31 & 98,32 & 63 & $\mathrm{c}$ \\
\hline PV 6 & $26^{\circ} 44,072^{\prime}$ & $' 67^{\circ} 17,148^{\prime}$ & CE & 52,39 & 0,93 & 15,22 & 7,76 & 0,12 & 7,16 & 8,66 & 3,44 & 1,81 & 0,37 & 1,15 & 99,02 & 62 & $\mathrm{a}$ \\
\hline PV 7 & $26^{\circ} 42,271^{\prime}$ & ' $67^{\circ} 14,923^{\prime}$ & $\mathrm{CE}$ & 50,79 & 1,22 & 15,09 & 7,91 & 0,15 & 8,72 & 8,92 & 3,45 & 1,82 & 0,48 & 0,08 & 98,63 & 66 & $\mathrm{~b}$ \\
\hline PV 7 & $26^{\circ} 42,134^{\prime}$ & ' $67^{\circ} 14,853^{\prime}$ & $\mathrm{CE}$ & 51,66 & 1,08 & 14,08 & 6,89 & 0,13 & 7,49 & 9,39 & 3,26 & 1,91 & 0,46 & 1,82 & 98,17 & 66 & b \\
\hline PV 7 & $26^{\circ} 42,420^{\prime}$ & $' 67^{\circ} 14,760^{\prime}$ & CE & 50,20 & 1,22 & 14,70 & 8,00 & 0,15 & 9,27 & 8,87 & 3,40 & 1,76 & 0,48 & 0,71 & 98,76 & 67 & e \\
\hline PV 7 & $26^{\circ} 42,000^{\prime}$ & $' 67^{\circ} 15,600^{\prime}$ & CE & 50,80 & 1,20 & 15,10 & 7,50 & 0,15 & 8,38 & 8,84 & 3,54 & 1,95 & 0,56 & 0,38 & 98,40 & 67 & $\mathrm{e}$ \\
\hline PV 9 & $26^{\circ} 45,492^{\prime}$ & $67^{\circ} 16,710^{\prime}$ & $\mathrm{M}$ & 53,27 & 1,07 & 15,30 & 7,43 & 0,13 & 7,82 & 7,94 & 3,55 & 1,76 & 0,30 & 0,80 & 98,56 & 65 & $\mathrm{c}$ \\
\hline PV 9 & $26^{\circ} 45,259^{\prime}$ & ' $67^{\circ} 16,589^{\prime}$ & $\mathrm{M}$ & 52,85 & 0,88 & 14,71 & 7,99 & 0,13 & 7,78 & 8,48 & 3,11 & 1,82 & 0,30 & 0,96 & 99,02 & 63 & $\mathrm{a}$ \\
\hline PV 10 & $26^{\circ} 45,552^{\prime}$ & ' $67^{\circ} 17,268^{\prime}$ & D & 52,71 & 1,13 & 15,56 & 7,77 & 0,13 & 7,96 & 8,17 & 3,58 & 1,69 & 0,31 & 0,65 & 99,01 & 65 & $\mathrm{c}$ \\
\hline PV 10 & $26^{\circ} 45,716^{\prime}$ & ' $67^{\circ} 17,105^{\prime}$ & D & 52,91 & 0,89 & 15,23 & 7,83 & 0,12 & 7,61 & 8,34 & 3,43 & 1,75 & 0,34 & 0,71 & 99,16 & 63 & $\mathrm{a}$ \\
\hline PV 11 & $26^{\circ} 51,895$ & ' $67^{\circ} 15,289^{\prime}$ & D & 54,62 & 0,95 & 15,55 & 6,52 & 0,13 & 6,48 & 7,45 & 3,38 & 2,38 & 0,28 & 0,92 & 98,66 & 64 & $\mathrm{~b}$ \\
\hline PV 13 & $26^{\circ} 53,064^{\prime}$ & ' $67^{\circ} 15,387^{\prime}$ & $\mathrm{CE}$ & 48,77 & 1,17 & 14,47 & 7,50 & 0,14 & 7,84 & 10,38 & 3,15 & 1,64 & 0,41 & 2,58 & 98,05 & 65 & $\mathrm{~b}$ \\
\hline PV 15 & $26^{\circ} 53,974^{\prime}$ & ' $67^{\circ} 16,497^{\prime}$ & $\mathrm{CE}$ & 47,53 & 1,28 & 15,20 & 9,18 & 0,16 & 10,30 & 10,06 & 2,81 & 1,41 & 0,45 & 0,55 & 98,93 & 67 & $\mathrm{~b}$ \\
\hline PV 18 & $26^{\circ} 51,042^{\prime}$ & $' 67^{\circ} 18,678^{\prime}$ & CE & 52,16 & 1,11 & 15,74 & 8,13 & 0,14 & 7,92 & 8,76 & 3,29 & 1,71 & 0,31 & 0,44 & 99,26 & 63 & $\mathrm{c}$ \\
\hline PV 19 & $26^{\circ} 50,970^{\prime}$ & $' 67^{\circ} 19,128^{\prime}$ & CE & 52,23 & 1,09 & 15,91 & 8,10 & 0,14 & 7,80 & 8,71 & 3,34 & 1,63 & 0,31 & - & 99,27 & 63 & $\mathrm{c}$ \\
\hline PV 19 & $26^{\circ} 50,542^{\prime}$ & ' $67^{\circ} 19,488^{\prime}$ & CE & 51,78 & 0,94 & 15,23 & 8,69 & 0,14 & 8,64 & 8,39 & 3,35 & 1,65 & 0,33 & - & 99,13 & 64 & $\mathrm{a}$ \\
\hline PV 20 & $26^{\circ} 50,298^{\prime}$ & ' $67^{\circ} 18,738^{\prime}$ & $\mathrm{M}$ & 54,31 & 1,11 & 15,20 & 7,61 & 0,13 & 7,53 & 7,43 & 3,51 & 2,04 & 0,33 & 0,49 & 99,20 & 64 & $\mathrm{c}$ \\
\hline PV 20 & $26^{\circ} 50,337^{\prime}$ & ' $67^{\circ} 18,640^{\prime}$ & $\mathrm{M}$ & 57,34 & 0,91 & 16,96 & 7,81 & 0,13 & 3,32 & 6,72 & 2,86 & 2,64 & 0,34 & 1,12 & 100,14 & 43 & $\mathrm{~b}$ \\
\hline PV 20 & $26^{\circ} 50,337^{\prime}$ & ${ }^{\prime} 67^{\circ} 18,640^{\prime}$ & $\mathrm{M}$ & 57,82 & 0,85 & 13,63 & 7,26 & 0,11 & 7,01 & 6,61 & 2,91 & 2,13 & 0,31 & 0,51 & 99,15 & 63 & $\mathrm{a}$ \\
\hline PV 21 & $26^{\circ} 49,860^{\prime}$ & ' $67^{\circ} 20,178^{\prime}$ & M & 53,61 & 1,00 & 15,63 & 8,21 & 0,13 & 7,48 & 7,84 & 3,14 & 1,92 & 0,33 & - & 99,28 & 62 & $\mathrm{a}$ \\
\hline PV 27 & $26^{\circ} 51,534^{\prime}$ & ' $67^{\circ} 18,210^{\prime}$ & $\mathrm{CE}$ & 54,87 & 0,95 & 15,43 & 6,93 & 0,12 & 6,45 & 7,68 & 3,26 & 2,26 & 0,27 & 0,63 & 98,23 & 62 & $\mathrm{c}$ \\
\hline
\end{tabular}

(*) Óxidos expresados en \% en peso y ajustados a 100\% en base anhidra. FeO*: Fe total; LOI: pérdida por calcinación. a. Este trabajo; b. Drew et al., 2009; c. Murray et al., 2015; d. Kay et al., 1994; e. Risse et al., 2013. CE: conos de escoria; D: domos; M: estructuras freatomagmáticas. 